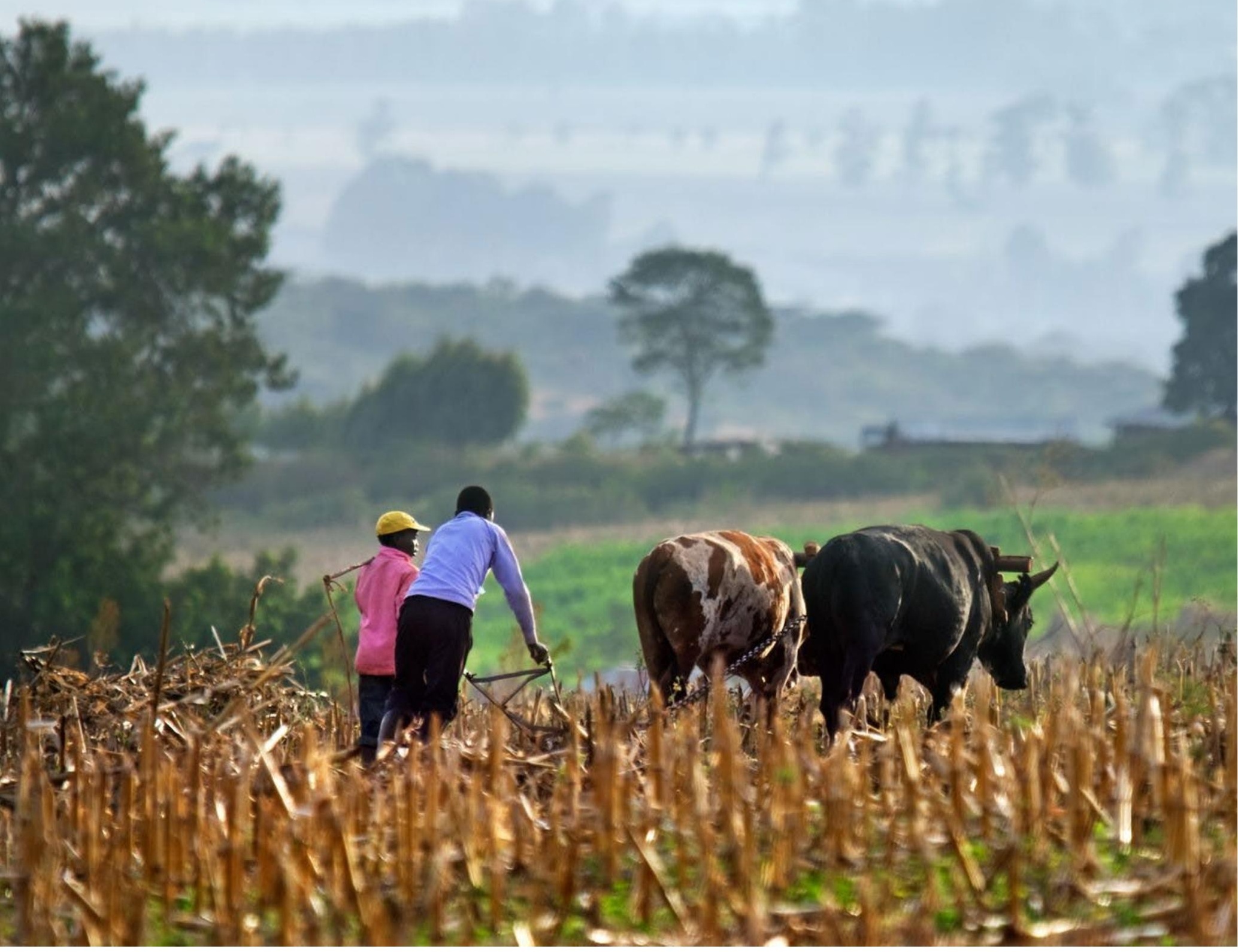

\title{
Tools for Transitions
}

An inventory of approaches, methods and tools for stakeholder engagement in developing transition pathways to sustainable food systems

Author(s): Susan de Koning, Wim de Haas, Nina de Roo, Marloes Kraan, Marijke Dijkshoorn-Dekker 


\section{Tools for Transitions}

An inventory of approaches, methods and tools for stakeholder engagement in developing transition pathways to sustainable food systems

Author(s): $\quad$ Susan de Koning, Wim de Haas, Nina de Roo, Marloes Kraan, Marijke Dijkshoorn-Dekker

Publication date: January $13^{\text {th }} 2021$

Wageningen Marine Research

IJmuiden, January $13^{\text {th }} 2021$

Wageningen Marine Research report C001/21 
Susan de Koning, Wim de Haas, Nina de Roo, Marloes Kraan, Marijke Dijkshoorn-DekkerSusan de Koning, Wim de Haas, Nina de Roo, Marloes Kraan, Marijke Dijkshoorn-Dekker. Tools for Transitions; An inventory of approaches, methods and tools for stakeholder engagement in developing transition pathways to sustainable food systems. Wageningen, Wageningen Marine Research, Wageningen Marine Research report C001/21.

This study was carried out by Wageningen University \& Research and was commissioned and financed by the Dutch Ministry of Agriculture, Nature and Food Quality within the context of the Knowledge Base programme 'Food Security and Valuing Water' (Transition pathways: project number KB-35-006001).

This report can be downloaded for free from https://doi.org/10.18174/538961

Wageningen Marine Research provides no printed copies of reports

Wageningen Marine Research is ISO 9001:2015 certified.

Photo credits: Byelikova Oksana / Shutterstock.com

\section{(C) Wageningen Marine Research}

Wageningen Marine Research, an institute Wageningen Marine Research accepts no liability for consequential damage, nor within the legal entity Stichting for damage resulting from applications of the results of work or other data Wageningen Research (a foundation under obtained from Wageningen Marine Research. Client indemnifies Wageningen Dutch private law) represented by Marine Research from claims of third parties in connection with this application. Dr. ir. J.T. Dijkman, Managing director All rights reserved. No part of this publication may be reproduced and / or published, photocopied or used in any other way without the written permission of the publisher or author.

KvK nr. 09098104,

WMR BTW nr. NL 8113.83.696.B16.

Code BIC/SWIFT address: RABONL2U

IBAN code: NL 73 RABO 0373599285 


\section{Contents}

\section{Summary}

$1 \quad$ Introduction $\quad 5$

1.1 Report objective $\quad 5$

1.2 Stakeholder engagement in developing transition pathways 5

$2 \quad$ Inventory method $\quad 8$

$\begin{array}{lll}2.1 & \text { Interviews } & 8\end{array}$

$\begin{array}{ll}2.2 \text { Survey } & 8\end{array}$

$\begin{array}{lll}2.3 & \text { Structure of the results } & 9\end{array}$

3 Approaches, methods and tools for transition pathway development 10

$\begin{array}{ll}3.1 & \text { Introduction }\end{array}$

3.2 Approaches 10

3.2.1 Stakeholder participation and the role of researchers $\quad 11$

3.2.2 Approaches $\quad 12$

3.3 Methods to define transition pathways with stakeholders 16

$\begin{array}{ll}\text { 3.3.1 Participatory forecasting } & 17\end{array}$

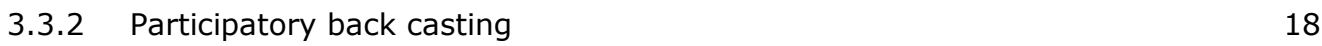

$\begin{array}{ll}\text { 3.3.3 Participatory design } & 19\end{array}$

$\begin{array}{ll}\text { 3.3.4 Participatory 'research in process' } & 20\end{array}$

$\begin{array}{lll}3.4 & \text { Tools } & 22\end{array}$

$\begin{array}{lll}3.4 .1 & \text { Selection tools } & 22\end{array}$

$\begin{array}{ll}3.4 .2 & \text { Evaluation tools }\end{array}$

$\begin{array}{lll}3.4 .3 & \text { Envisioning and forecasting tools } & 24\end{array}$

4 General principles for the choice of approaches, methods and tools 26

$\begin{array}{lll}4.1 & \text { Principles of responsible transition pathways } & 26\end{array}$

4.2 Approaches, methods and tools and the five principles 28

$\begin{array}{lll}4.3 & \text { Different contexts for transition pathways } & 29\end{array}$

$\begin{array}{lr}\text { References } & 31\end{array}$

$\begin{array}{lr}\text { Appendix } 1 & 36\end{array}$

$\begin{array}{lr}\text { Appendix } 2 & 37\end{array}$

$\begin{array}{lr}\text { Justification } & 39\end{array}$ 


\section{Summary}

The global food system is facing big problems, such as global food security for a growing population, climate change and biodiversity conservation, which ask for transitions of the food system. To analyze or contribute to a food system transition it is important to explore possible 'transition pathways' towards more sustainable food systems. A 'transition pathway' is a narrative that describes how a new or adapted system may evolve out of a previous system. To create impact pathways need to be developed with the engagement of stakeholders. In this document, an overview is given of approaches, methods and tools which are relevant for stakeholder engagement in the development of transition pathways towards sustainable food systems. The report is intended for those who are involved in transition initiatives in a role as researcher, consultant of process facilitator.

Approaches refer to the paradigms behind the way research is done. Methods are the strategies and processes that are utilized in - here - the development of transition pathways. Tools are the means that help to fulfil a task in a (research) project, for instance to collect, analyse or present information. The number of tools is endless.

We distinguished several approaches:

- Participatory research

- Action research (e.g. multi-stakeholder partnerships)

- $\quad$ Shared knowledge creation (e.g. community of practice)

- Combinations of models and participation (e.g. transition support system approach)

- Issue advocacy

Next to that, we specifically describe the (different) role(s) of researchers in stakeholder involvement. Stakeholder involvement requires new skills of researchers. It helps if they have a broad experience and can understand several worlds.

Approaches come to expression in the used methods. We distinguish:

- Interactive scenario-building (e.g. participatory mapping)

- Back-casting (e.g. socio-technical scenarios)

- Participatory design (e.g. reflexive interactive design)

- Participatory 'research in process'

Within these methods, different tools for participant selection, evaluation and envisioning and forecasting can be used. For example:

- Interest-power grid

- SWOT-analysis

- Food Systems Decision Support System

- Rich picture

- PIP-approach

- Four Quadrants of Change

- Map Table

The choice of relevant methods and tools can be based on the following general principles:

- Integral approach: Methods and tools need to support an integral approach

- Inclusiveness and dialogue: Approaches, methods and tools should be inclusive and promote dialogue

- Contextuality: Methods and tools should take cultural context into account

- Long term orientation: Methods and tools should be aimed at the long-term

- Focus on tangible actions: Methods and tools should facilitate concrete actions for change 


\section{Introduction}

\subsection{Report objective}

While sustainability transitions are concerned with radical transformations of sociotechnical systems (e.g. energy, food), research in this field remains relatively quiet about the participatory processes that bring citizens closer to democratic ideals and inclusive transitions (Rut, Davies, and Ng 2020).

The food system is facing big problems, such as global food security for a growing population, climate change and biodiversity conservation (Béné et al. 2019). These interrelated challenges can be regarded as wicked problems. Wicked problems are ever-changing, they involve a high degree of scientific uncertainty and are related to conflicting values among different stakeholders (Dentoni and Bitzer 2015). Also, wicked problems have no clear starting point or ending (Jentoft and Chuenpagdee 2009). These wicked problems challenge the food system to radical transformations throughout the whole system (McKee et al. 2014). To be able to achieve radical system transformations, different pathways towards these transformations can be identified, in which stakeholder engagement is key. Stakeholders influence the direction and speed of the transitions and can hinder or enable the processes that lead to system change.

In this document, an overview is given of approaches, methods and tools which are relevant for stakeholder engagement in the development of transition pathways to sustainable food systems. To date, many toolboxes of stakeholder engagement already exist (Competentiecentrum Transities 2009; GAP2 2015; CDAIS 2017). However, in this report we specifically focus on approaches, methods and tools for stakeholder engagement in defining transition pathways in food system transitions. The aim is not to give an exhaustive overview or critical review current approaches, methods and tools, but to give a concise overview with practical examples of approaches methods and tools. Most approaches, methods and tools are used by researchers of Wageningen University and Research, this report is therefore mainly built on their knowledge and experience. The report is intended for those who are involved in initiatives aimed at the transition of the food system in a role as researcher, consultant of process facilitator. The report can also be important for impact investors, change agents, policy makers or donors behind these kind of transition initiatives and all others who take part in the transition of the food system. It is part of the KB project Transition Pathways which is aimed at developing and testing an approach to explore and analyse possible transition pathways towards sustainable agro-food systems in LMIC. Stakeholder engagement is inseparably linked to this goal.

\subsection{Stakeholder engagement in developing transition pathways}

A food systems transition perspective implies a radical form of change, which affect not only production systems but also consumption patterns and governance arrangements. A transition process is non-linear, difficult to predict in detail, and involves many parties (actors). Controlling the process of a transition as a whole is impossible, even if someone would want to (Grin et al. 2010). Some examples of historical transitions are the industrial revolution and the rise of capitalism. More recent examples of on-going transitions are the energy transition or the modernisation of agriculture in many Low- and Middle-Income Countries (LMIC).

An initiative or a project which aims to contribute to a food system transition must not only understand the technological aspect but also the social and political aspect of food systems. Technological, socio-economic and political regimes all influence the potential uptake of any initiative that tries to contribute to a transition of the system (Geels \& Schot, 2007; Lowe, Phillipson, \& Lee, 
2008). For a proper identification of their position and opportunities, these initiatives need to explore and define pathways the transition can possibly take.

A 'transition pathway' is a narrative that describes how a new or adapted system may evolve out of a previous system. This narrative is based on several assumptions about how change can be understood. Because a transition encompasses both technical and non-technical change, transition pathways will show the same diversity even more so because they play out in different contexts which affect related processes. 'Transition Pathway' can be used retrospectively, to describe past transitions, as well as prospectively, to assess possible future transitions. Transition pathways come in many forms (Geels and Schot 2007) and can be used to envision system change or reflect on system change.

The key function of exploring future transition pathways is to make radical scenarios 'imaginable,' rather than 'unrealistic'. If stakeholders have an idea of possible pathways, they can better distinguish how their actions fit into major developments, how they can be taken up and which actions are more and less adequate.

Within the exploration of transition pathways, it can be useful to distinguish three types of knowledge: systems knowledge, target knowledge and transformation knowledge (see Fout! Verwijzingsbron niet gevonden.). Together these three forms of knowledge can enhance our understanding of and how to facilitate transitions (Pohl and Hirsch Hadorn 2007).

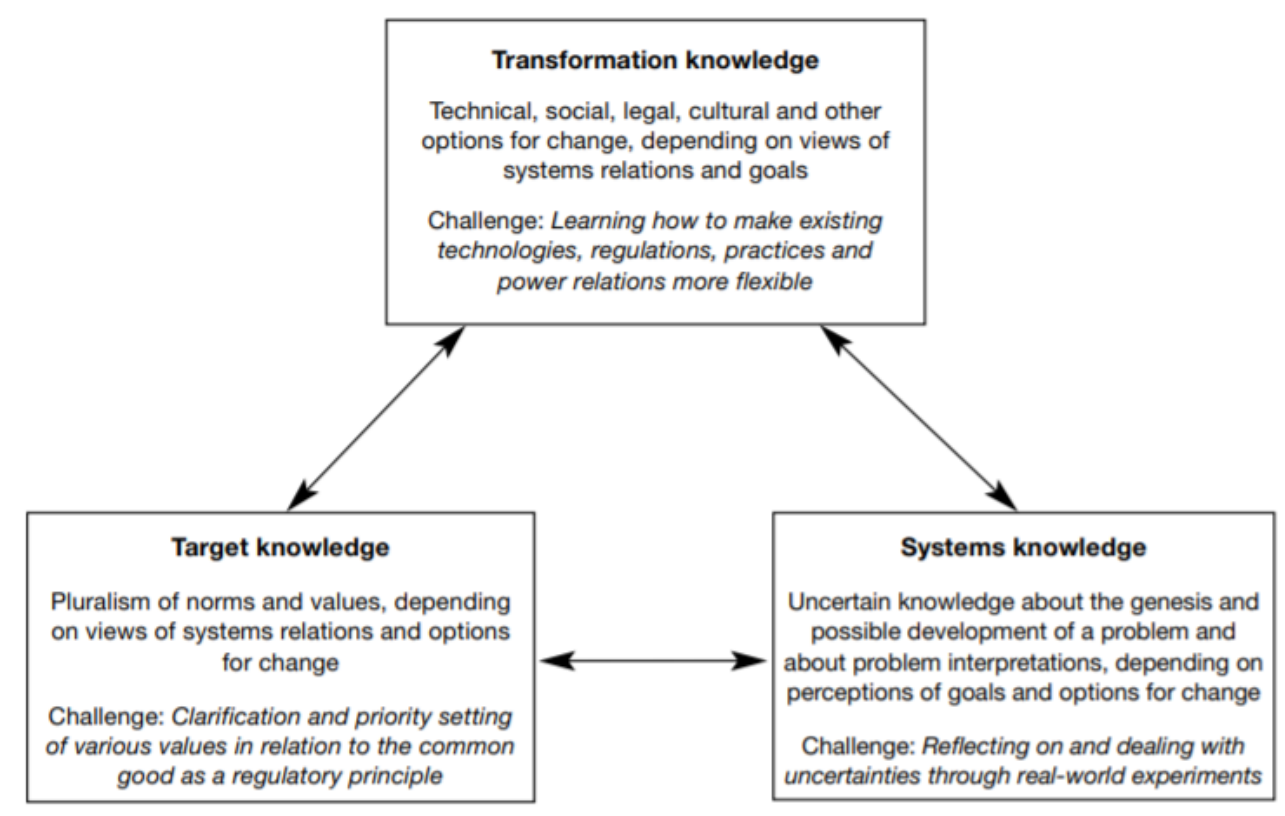

Figure 1 Interdependencies between three types of knowledge within transdisciplinary research

With regards to the challenges within the development of systems, target and transformation knowledge, it is evident that stakeholders are needed to develop this knowledge. To develop systems knowledge, we need to reflect on uncertainties, the different problem interpretations of stakeholders and the goals and options for change which are related to these interpretations. To develop target knowledge, we need to understand the different norms and values of stakeholders underpinning the problem interpretations and options for change. To develop transformation knowledge, we need to understand the different options of change from a technical, social, legal and cultural perspective (Pohl and Hirsch Hadorn 2007). This is important for all working in initiatives (research, policy developments, technology development, actor arrangements, etc.) aiming at the transition of the food system should be aware of the many different 'knowledges' and values which are involved in environmental issues (Reed 2008). Therefore, we argue that stakeholder engagement is a necessity within the development of transition pathways for food systems. 
Stakeholder involvement in exploring and defining transition pathways can be supported on different levels.

- $\quad$ First, by following an approach which intrinsically includes the contribution of stakeholders, recognises the value of different types of knowledge and uses non-linear development concepts. A transdisciplinary approach integrates paradigms from different disciplines and uses participatory methods in solving applied problems (Pohl \& Hirsch Hadorn, 2007).

- Second, by following a method which is open, inclusive and have a reflexive nature Methods are usually applications of an approach in a concrete form, often by distinguishing different steps.

- Third, by using tools that support exploration, positioning and identifying pathways and actions from the perspective of stakeholders. 


\section{Inventory method}

In this study, we have applied several methods to draw up an inventory of transition approaches, methods and tools, as used by the Wageningen Research Institutes. As a start, we have performed a literature study on general principles in engaging stakeholders in food systems transitions. We have searched within Google Scholar for the following keywords; stakeholder, engagement, transition, back-casting. We chose to focus on backcasting instead of scenario studies in general, as transition pathways are generally constructed through back-casting instead of forecasting. Hence, 'scenario' was not included as a keyword. Based on the abstract of the found literature, we have determined whether we should read and include the described tools and approaches.

\subsection{Interviews}

To establish the different tools and approaches used by scientists of Wageningen Research institutes, we have interviewed scientists participating in the project Transition Pathways, which is part of the KB theme Food Security and Valuing Water, to gather the experiences of the different Wageningen Research (WR) institutes. The scientists were informed beforehand on the content and set-up of the interview and were encouraged to discuss the approaches used in their institute with their colleagues as a preparation for the interview. Wageningen Research institutes which are participating in this project are Wageningen Economic Research, Wageningen Environmental Research, Wageningen Food \& Biobased Research, Wageningen Livestock Research, Wageningen Marine Research, Wageningen Plant Research and Wageningen Centre for Development Innovation. Furthermore, all these participating researchers have studied or have worked on stakeholder engagement in one or more KB projects in relation to food systems. In total, we have interviewed 8 researchers, one of each institute. At Wageningen Marine Research, two researchers were interviewed together. The topic guide of the interviews can be found in Appendix 1.

\subsection{Survey}

After the interviews, we have developed an online survey which was aimed at collecting additional tools which were not discussed in the interviews. The questions of the survey can be found in Appendix 2. The survey was developed after the interviews took place. Based on the interviews, we reflected with the group of 13 researchers on the results, which we felt lacked certain approaches, methods and tools that might be suitable for the purpose of this report. Next to that, we felt a need for more detailed information concerning the possible function of the approaches, methods and tools within transition pathway development and food system transitions. These types of questions are therefore added in the survey. The survey was filled in by the same researchers that were interviewed, and by other researchers which are part of the KB project Transition Pathways and work in project related to food system transitions. Before filling in the survey, the researchers (13 in total) were asked to inform colleagues about the inventory and ask which tools they use in stakeholder engagement in transition pathway development. 24 tools were gathered through the survey, of which 18 had not yet been discussed in the interviews. As follows from our inventory method, we focussed on researchers known to work with stakeholders in food system transitions, using a snowball method. Therefore, the report is not an exhaustive overview of approaches, methods and tools, but gives rather a concise overview of approaches, methods and tools used at Wageningen Research which can be relevant for other scholars or transition facilitators in engaging stakeholders in transition pathway development in food system transitions. 


\subsection{Structure of the results}

The approaches, methods and tools collected through the interviews, case studies and the literature study are summarized and categorized in chapter 3. As every stakeholder engagement process is different and while there is a broad scope of approaches, methods and tools available, we decided to develop generals to assess the suitability of the described approaches, methods and tools for engaging stakeholders in the development of transition pathways. These principles are based on the experience of the Wageningen Research researchers, literature on stakeholder participation and sustainability transitions, as described in the introduction and the Principles of Responsible Research and Innovation (Burget et al. 2017). The principles are described in chapter 4, followed by a description of different archetypical situations in transition pathway development and the approaches, methods and tools which are suitable in those situations. 


\section{Approaches, methods and tools for transition pathway development}

\subsection{Introduction}

In the introduction we shortly mentioned the terms approaches, methods and tools, but what are the differences between these three? In this report we have defined them as follows.

Approaches refer to the paradigms behind the way research is done. Approaches include broad assumptions on basic concepts like truth, facts, reality, etc.; thematic preferences; preferences for certain methods in which the approach is showed. In this report we have included approaches that are aimed at the participatory development of transition pathways.

In section 3.2 we describe the approaches that meet these requirements. While different approaches imply different roles of researches, we also pay attention to the role of researchers in this paragraph.

Methods are the strategies and processes that are utilized in - here - the development of transition pathways. Some methods and approaches are closely linked. They are sometimes classified with an adjective that indicates which approach is followed: feministic methods, participatory methods, etc. Section 3.3. gives and overview of methods that fit in the scope of this study.

Tools are the means that help to fulfil a task in a (research) project, for instance to collect, analyse or present information. The number of tools is endless. In this study we concentrate on the tools that enable the defining of transition pathways with stakeholders. In section 3.4 we distinguish three types of tools:

- Tools that help to understand the food system or evaluate possible impacts of design or projected actions;

- $\quad$ Tools which help stakeholders to develop (together) their ideas on novel or alternative (parts of) the food system;

- Tools to organise the cooperation with and between stakeholders.

There is another category of tools to facilitate focused conversations and discussions on a micro level. For instance: clustering sticky notes, brainstorming, mind mapping, role playing, etc. This category is beyond the scope of this study.

\subsection{Approaches}

In this subsection we will describe different approaches that one can take towards stakeholder engagement in transition pathway development, based on our interviews and survey. First, we start off with some general principles on stakeholder participation and the role of researchers in stakeholder engagement, based on literature and findings of the interviews. After that, we will describe a twodimensional field on which several approaches appear. Then we describe these approaches:

participatory research, action research, shared knowledge creation, stakeholder participation and decision support and speaking truth to power. In this section, we will give a short description of the different approaches. 


\subsubsection{Stakeholder participation and the role of researchers}

\section{Stakeholder participation}

Reed (2008) developed 8 best practices in stakeholder participation in environmental management. Although his work is not focused on the development of transition pathways but rather on participation in decision-making, it is relevant as transition pathways should ultimately impact decision-making and include decision-makers as stakeholders. Reed's main argument is that instead of seeing participation as a tool within decision-making, it should be regarded as an essential process within decision-making. Based on literature, Reed established the following 8 best-practices:

1. Stakeholder participation needs to be underpinned by a philosophy that emphasizes empowerment, equity, trust and learning.;

2. Where relevant, stakeholder participation should be considered as early as possible throughout the process;

3. Relevant stakeholders need to be analyzed and represented systematically;

4. Clear objectives for the participatory process need to be agreed among stakeholders at the onset;

5. Methods should be selected and tailored to the decision-making context, considering the objectives, type of participants and appropriate level of engagement;

6. Highly skilled facilitation is essential;

7. Local and scientific knowledges should be integrated;

8. Participation should be institutionalized, meaning that the organization behind the participatory process is open or fit to incorporate decisions that are derived through participatory processes into 'regular' decision-making

These 8 best practices are relevant for all approaches which will be described in this section and can therefore be useful to reflect on the way you engage stakeholders in your (future) project(s) or aid in the design or choice of approaches, methods and tools. Although the described approaches, methods and tools can be very specific, the 8 best practices are relevant to consider when putting the approaches, methods and tools into practice.

\section{Role of researchers}

The collaboration with stakeholders in transitions asks more from a researcher than just being the expert. Researchers can also take up roles as advisor, arbiter, issue advocate or broker (Pielke, 2007). In some cases, researchers take up even a role as mediator, for instance in the application of the TSS approach. The possibility to take different roles and to switch between roles requires experience and competences, which normally do not belong to the standard scientific competences. Furthermore, in project with stakeholders, researchers should be open to learn from stakeholders, and to critically reflect on their research. A lot of researchers are for instance not inclined to discuss their results with stakeholders, although it is a very minimal and easy to accomplish level of stakeholder engagement which can be very valuable for the research.

Researches are not only related to stakeholders but are part of a so-called Interaction Triangle (Röckmann et al. 2015). This triangle relates to the relationships between three parties: decision makers, stakeholders and researchers. The relationship between stakeholders and researchers is about the criterion Credibility; between researchers and decision-makers about the criterion Salience; between decision-makers and stakeholders about the criterion Legitimacy (which also may be the object of research for researchers). For researchers, it is important to be aware which of these three they are dealing with, in order to fulfill their role stronger and better.

What is helpful in stakeholder engagement are 'boundary people', people who have taken part of both worlds and are trusted in both worlds. For instance, because they worked in several sectors, or have family or for any other reason. Within science, the same goes for different disciplines: social scientists understanding natural sciences, and vice versa. However, whereas boundary people can aid in bridging between the scientific world and the reality stakeholders live in, researchers with more distance to the subject and the stakeholders can aid in adding new viewpoints to the matter and thinking beyond the specific sector or situation. 
Not only researchers can play an important role in stakeholder engagement processes in food system transitions, other types of organizations and institutions can also take up such a role, by becoming innovation brokers or boundary workers (Klerkx, Hall, and Leeuwis 2009). Innovation brokers have a bridging function between different stakeholders whom are part of or could contribute to an innovation or transition. To do so effectively, innovation brokers or boundary workers should first understand the complexity of the system, to be able to understand what the innovation should be aimed at and how different stakeholders can play their part in the innovation. A large challenge hereby is to deal with issues of neutrality, especially when working in developing countries (Klerkx, Hall, and Leeuwis 2009). Many projects have a lot of 'multi-stakeholder force', they consist of representatives of all-important parties. But if these representatives represent thousands of people (like farmers), one can question how representative they are. Cooperations often have other stakes then the farmers themselves. Furthermore, using focus groups to study these representatives and their partnerships, is not always enough to understand their position. This is in general a challenge for both research institutes and other types of organizations: transitions often are very political. In some developing countries, the government is very strong, leaving no space for input from stakeholders. Therefore, when engaging stakeholders in such settings, it must be clear what the goal of the engagement is, to prevent disappointment from stakeholders. Furthermore, all methods, tools and theories should be explained in a way that all stakeholders understand. As a researcher, a certain method can be useful for understanding a system and its stakeholders. But if the stakeholders do not understand the merit of the method, it will not aid in engaging them in the research and the transition.

Another difficult, but important consideration for researchers, is that funding for research is often sector based. When studying poverty in a value chain of a certain commodity, like cacao, the commissioning party is often related to that commodity, and possible solutions need to be related to that commodity or value chain. While, maybe, the solution to the question might be outside of this value chain. This is also reflected in the methods which are used, such as sector transformations (WCDI 2020a) and the Robust, Reliable and Resilient principles (Bebe et al. 2017). A food systems approach is therefore a good way to combine zooming out with zooming in on a project but finding enough resources and willingness for such a complex task might be difficult.

\subsubsection{Approaches}

\section{Two-dimensional field to distinguish approaches}

Approaches differ from each other on fundamental aspects. Two important aspects are:

- The relationship with the stakeholders. Is the project (i.e. defining transition pathways) aimed at specific stakeholders, which can vary from small farmers in an area to a NGO or a company (advocacy model), or is it aimed at multiple stakeholders, whether or not with opposing interests (broker model).

- The kind of research. Is this research in the tradition of 'normal' science, aimed at 'objective' information and knowledge that can be used in the preparation of transition pathways, or is it research in uncertainty which is open to the influence of the stakeholders, who participate in data collection and the formulation of conclusions (post-normal science, see Ravetz \& Funtowicz 1993). In the latter case research is part of a joint process of gaining insights.

These two dimensions shape a field on which the to four ideal typical approaches, with which the described approaches can be positioned (see Table 1). 
Table 1 Approaches between normal and post normal science, and between single and multiple stakeholder engagement

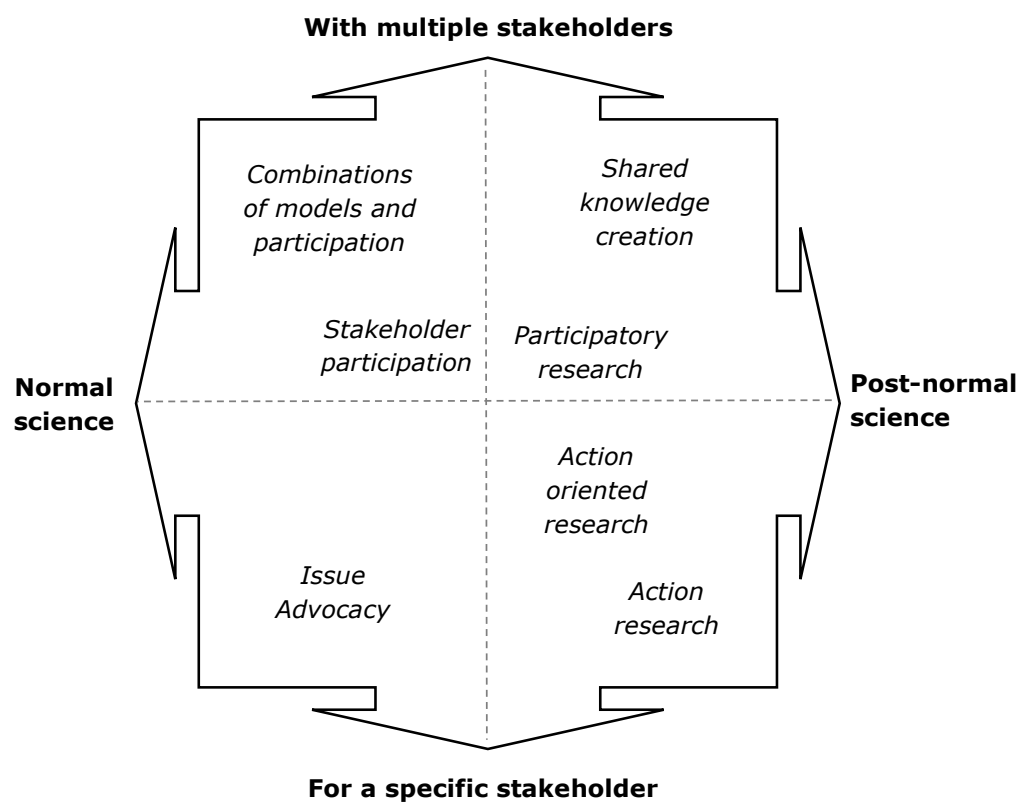

\section{Participatory research}

In participatory research, research is not only performed by researchers, but by a combination of researchers and stakeholders. Participants can be part of all or several stages of the research process, like the development of research questions, carrying out research activities, analyzing research or interpreting research results. The GAP2 project (Connecting Science, Stakeholders and Policy), funded by the European Commission, aimed to bundle the experiences of fisheries scientists in participatory research together in a good practice guide on participatory research (Mackinson et al. 2015). Stakeholder engagement in transition pathway development can be in the form of participatory research, for instance if there are (scientific) questions which can aid in understanding possible transition pathways. In the GAP2 project, main principles for participatory research have been formulated. Here we summarize them, including explanations of the principles tailored at the application in transition pathways:

1. Inclusivity: Search for stakeholders in a broad area, start with this as early as possible, include stakeholders with different views. Moreover, make clear that the outcomes of the transition pathway, will not directly lead to management outcomes which are in line with the established pathway;

2. Effective facilitation: Involving neutral and skilled facilitators in the transition pathway development is crucial to overcome issues like prejudices among stakeholders and to create a space where stakeholders feel free to be open minded an honest;

3. Joint ownership of knowledge: Discuss the methods and process of the development of the transition pathway together with the participants, so the pathway(s) will really be a shared product of all kind of stakeholders, not just the leading organization;

4. Overcoming institutional barriers: Make sure that is enough funding to go through the whole participation process, and to make sure that stakeholders with fewer financial means are compensated for their participation. When scientists are involved in the process, they should be aware that participation processes like transition pathway development takes a long time, and that the results are not always easily publishable from the current perspective of natural science;

5. Prioritizing communication: Frequent contact between the organizing party and the involved stakeholders is key and is preferably as personal as possible. Within the development of the transition pathways, stakeholders should agree on terms and concepts, which are preferably also defined by the stakeholders in the beginning of the process. Furthermore, the organizing party should assure that the outcomes of the participation process is also communicated to non-participating groups who are affected by a possible transition; 
6. Planning participatively: Involve stakeholders from the onset of the process, especially in the development of the goal and the methods which will be used. Spend time to build trust among stakeholders and between stakeholders and the organizing party;

7. Battling participation fatigue: As participation in the transition pathway development can costs stakeholders a lot of time which they cannot spend on earning a living, explicitly discussing different possibilities for meetings which suits best for the stakeholders is important.

For an overview of examples of participative research in practice. The Participatory Learning and Action (PLA) notes archive from the International Institute for Environment and Development (IIED 2020), bundles experiences with participative research from all over the world and is a useful inspirational reference (IIED 2020).

\section{Action research}

Action research or action-oriented research is an approach in which the researcher plays an active role. In the light of stakeholder engagement processes, the researcher is thus not only an observer, he or she is also part of the research, for instance as a facilitator or innovation broker. The aim of such research is not only answering research questions, but also contributing to change. Action research can therefore be very suitable for research into transitions. At Wageningen Centre for Development Innovation, there is for instance a lot of experience in facilitating Multi-Stakeholder Partnerships (MSPs) (Brouwer, Hemmati, and Woodhill 2019). Based on this experience, a guide for the development of effective partnerships has been developed (Brouwer et al. 2016). MSPs are aimed at working on engagement and change, through the focus on getting from connection to commitment. The main principles of MSPs are listed below:

1. Embrace systemic change: regard the complexity of the system related to the MSP objectives, design interventions through multiple cycles of planning, action and reflection.

2. Transform institutions: MSPs should stimulate participants in critically reflecting on their own institutions and the institutions they want to affect through the MSP.

3. Work with power: be aware of power differences in the system and within the MSP and support disadvantaged groups to create a level playing field.

4. Deal with conflict: conflicts within MSPs must not be ignored or kept aside but needs to be addressed openly and handled constructively.

5. Communicate effectively: participants need to be able to listen to others and articulate their own ideas and views, which can be facilitated through specific exercises (tools) or by stimulating participants to reflect on their own their own way of communications and paradigms which form the basis of their judgement of other participants.

6. Promote collaborative leadership: leaders within MSPs must stimulate the collaborative nature of the MSP, by supporting the overall approach of finding answers together. This type of leadership is highly situational, finding suitable leaders for MSPs must therefore be based on a thorough analysis of the relations between stakeholders and cultural, economic and political aspects which influence these relations.

7. Foster participatory learning: stakeholders need to understand each other, explore common concerns and ambitions, generate new ideas and take joint action. This can be accomplished by using participatory methods and tools in experimental learning cycles. Participatory methods are described in section 3.3 and 3.4.

MSPs can be useful in food system transitions, especially when addressing one specific issue or sector However, MSPs are not especially designed for transition pathway development, but are rather useful for long term stakeholder engagement in food system transitions. If a project can last over the years, MSPs are a good choice to work with several stakeholders on a transition pathway, going through the different stages of the transition process.

\section{Shared-knowledge creation}

A community of practice is an approach in which there is no specific research question, but where the aim is to learn from each other and to innovate in interaction (Steins et al., 2020, Blackmore 2010) . A community of practice consists of a group of stakeholders working in the same field or sector, or working on a shared problem or goals from a different perspective. As transitions are long-term 
processes, a community of practice can aid stakeholders in developing new practices which aid in transitioning. Community of practices can develop independently but can be supported by research institutes or organizations with the competence to facilitate a community of practice. This is a very open-ended form of shared-knowledge creation, with a wide range of participants solely connected by shared interests or stakes. In community of practices, participants join to learn about a subject or topic in an informal environment, but also to establish a network and learn from others (Gray 2004). In situations where the desired future (from a certain perspective) is clear but the transition pathway is not, communities of practice can aid in connecting stakeholders and finding solutions or pathways through interaction and social learning. An example of a community of practice which is established to aid a (food system) transition is the Community of Practice Blue Innovation North Sea. This community of practice is established to form a platform for current users and potential users of the North Sea, to search together for possibilities to use the limited space at the North Sea for new forms of food production and other uses, like energy production or nature development. Within the community of practice, knowledge is exchanged, and parties seek collaboration to enable the development of new or more sustainable ways of using the North Sea.

\section{Stakeholder participation and decision support}

An approach in stakeholder engagement in decision-making regarding transitions is the combination of stakeholder participation and decision support tools. This approach is step-wise described in the Transition Support System approach (TSS)(Dijkshoorn-Dekker et al. 2020). The main aspect is the stakeholder process, in which decision support tools and data are integrated with the consensus of stakeholders. Within the TSS approach, future projections of food security, or other complex issues, are discussed as well as the action perspectives and their potential impacts. In this regard, the TSS approach facilitates ex-ante evaluation. TSS consists of 5 steps, in which stakeholders participate continuously (see Figure 2):

1. Determine urgency;

2. Scenario analysis;

3. In-depth analysis, in which the models are used as a basis for deliberation, gives more insight into possible scenarios;

4. Insight into the future, visual insights into the potential outcomes of different courses of action perspectives;

5. Impact evaluation.

The TSS approach is characterized by a continuous interaction of researchers with stakeholders although it allows for a dynamic composition of the group of stakeholders involved. The approach enables the different stakeholders to jointly explore potential future pathways towards sustainable, food-secure, and livable environments, and to reach supported and tenable solutions. The TSS approach provides insight into the different actions perspectives, and offers policy makers, the business community, and other organizations tools to change their policy and strategy. 


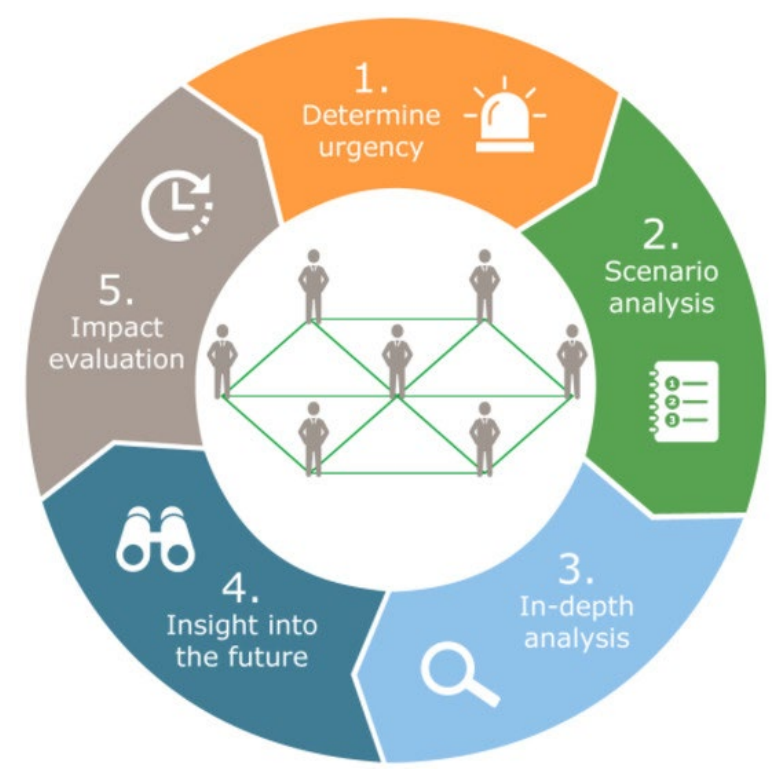

Figure 2 The five steps of the TSS (Dijkshoorn-Dekker et al. 2020)

\section{Issue Advocacy}

This is an approach in which facts and scientific insights, are gathered for a citizens initiative to influence governments or other powerful parties. In issue advocacy (term taken from Pielke, 2007) the implications of research are used for a particular stakeholder group, mostly one without much power to change situations. The role of the researcher is not neutral, she takes sides. It is a form of advocacy, which has a great faith in facts and figures and assumes that normal science has enough power to bring about change. In many cases this approach is applied against polluting industries, but it can also be aimed at the development of alternative transition pathways, to enforce participation or to strengthen running processes of participation.

\subsection{Methods to define transition pathways with stakeholders}

In the introduction of this chapter, methods are defined as the strategies and processes that are utilized in - here - the development of transition pathways. Some methods and approaches are closely linked, but different methods can fit in one approach.

With the content of the transition pathway, one can try to answer several questions together with stakeholders through pathway construction (Wangel 2011):

- What can change? (objects)

- How could change take place? (measures)

- Who could change? (agency)

The first two questions are often answered in transition pathways, however, the last one often remains unconsidered and therefore unanswered. Agency refers to the ability of people or organizations to act, and should be considered to understand who could contribute to a transition, how they could contribute and who is left out or behind in a transition pathway (Wangel 2011). Within a sociotechnical transition, the social dimension needs to be addressed (Haasnoot, Kraan, and Bush 2016).

We describe the methods for defining transition pathways in the next four paragraphs. All methods include: an old and a new situation, the steps between the old and the new, and the necessary interventions to realize the new situation. All methods can be applied in processes with stakeholders. But each paragraph emphasizes a different aspect.

- 3.3.1. Forecasting: emphasis on possible pathways seen from the present

- 3.3.2 Backcasting: emphasis on possible pathways seen from a vision on the future 
- 3.3.3 Design: emphasis on the new: new product, a new production system, a new way to cooperate, a new organisation.

- $\quad$ 3.3.4 Process: emphasis on assessing possible interventions pathways during participatory processes

\subsubsection{Participatory forecasting}

When developing transition pathways, stakeholders should be stimulated to develop multiple possible pathways, based on different uncertainties and the possible windows-of-opportunities that could develop out of these uncertainties (Sondeijker et al. 2006). The main goals of the development pathways are, according to Sondeijker et al. (2006), to describe and acknowledge the different uncertainties, to develop different options and prevent a deadlock situation, and to give stakeholders space and motivation to look for new directions when searching for solutions. With the content of the pathways, facilitators should stimulate stakeholders to create integral, coherent and consistent storylines, focused on a translation of short-term problems to long term sustainable change (Sondeijker et al. 2006).

\section{Interactive scenario building}

Scenarios are forms of future exploration in which uncertainties are systematically explored. There are different types of scenarios e.g. are they focused on desired futures or expected futures, or are they oriented at possible actions or at general developments. The development of scenarios begin with the analysis of the situation, continues with the defining of driving forces, which are usually used to form a matrix with two axes with $\mathrm{n}$ each axis a relevant and important development. Each quadrant then produces a scenario that is described in terms of a storyline. Here we are mainly focused on scenarios that are developed with stakeholders. In this case, the stakeholders define the problem, appoint the driving forces and together choose the scenarios that can be based on it. The development of the storylines behind each scenario can then be worked out in subgroups. Interactive scenario building fits well in an approach with multiple stakeholders and can be combined with a traditional research approach, in which the researches deliver information on driving forces and use the scenarios as input for model calculations, but also in an open research approach in which all steps are taken together.

Specific types of participatory forecasting are the following.

\section{Participatory mapping}

In the GAP2 project on stakeholder engagement in fisheries research and policy, several tools are mentioned which could be relevant to use in the development of transition pathways. In transitions with a strong spatial aspect, participatory mapping could be useful. Stakeholders draw maps of their knowledge on the issue, including both qualitative and quantitative information (Mackinson et al. 2015). In a next step, stakeholders could draw a map of their vision on the future, to which a transition pathway could lead. A congregation of the different current and future maps could form the basis of group discussions on how to back-cast from the future map to the current map. When working together with scientists with aim to model the possible outcomes of a transition, participatory modelling could be useful. In participatory modelling, the knowledge of stakeholders is integrated in the development of the model, as well as in the choice of which pathways will be assessed through use of the model (Mackinson et al. 2015).

\section{QUICKScan}

QUICKScan is an example of a methodology which combines spatial models and participation. QUICKScan uses moderated participatory workshops bringing together a wide range of stakeholders. In these workshops jointly an expert system is built in a spatially explicit tool with a strong focus on visualization of results, to model the impact of strategies or policy options. (Verweij et al., 2016; Verweij 2020). QUICKScan is a method which can be used to guide participatory processes concerning spatially explicit goals and/or problems (Winograd et al. 2013). In transition pathway development, it could aid in building, visualizing and assessing the impact of different transition pathways. A QUICKScan is always guided by a facilitator and a modeler / operator. The modelling is based on input of the participants, but also serves as input for the discussion between participants (Winograd et al. 2013). 


\subsubsection{Participatory back casting}

Quist and Vergragt (2006) described the steps which need to be taken when working on transition pathways together with stakeholders, divided in three stages. First, a long-term vision must be established. The problem must be defined, and a future vision must be developed (see methods) followed by a back-casting process. As described earlier in this paragraph, we would call this the development of a transition pathway. Starting with the future vision, the steps which need to be taken to connect the future vision to the current situation need to be described. Second, based on these steps, short term actions which can aid in taking these steps need to be described and put into a concrete action plan. Lastly, to implement these actions, roles need to be defined and cooperation between stakeholders needs to be (semi-)formalized. Next to that, a research agenda to support the transition needs to be implemented.

Before starting the development of transition pathways with stakeholders, so-called socio-technical visions must be established according to Smith and Stirling (2008). These visions are political in nature, as they should trigger the investment of national and regional governments in the transitions. However, these visions should remain open to debate, and must be adapted when new insights arise. The main requirement for a vision is that it provides a solution to the problem which is determined by the stakeholders. Therefore, stakeholders must be engaged in the establishment of this vision. Adding to this, Wangel (2011) explained that in the development of transition pathways, this future vision should not be rigid, but rather seen as a moving target. When establishing visions for the development of transition pathways, it is important to understand that the vision of the future should be relevant to the stakeholders, they should understand how the present is linked to the future. When thinking about future solutions, not only pioneers should be considered and consulted, but the people who are not yet changing their practices. As a researcher or process facilitator you need to understand what the needs of the different stakeholder groups are, what they need to be able to be part of a transition and what they think a transition could look like. Moreover, a vision for the future should not only be wishful thinking, it should acknowledge the fact that within a transition, there will always be winners and losers. When a vision is very positive for all stakeholders but not realistic, it will be impossible to make the transition towards this vision. An example of WR research in which future visions were developed with stakeholders is the European Agrilink Project (INRA Transfert 2019).

As indicated by literature in this section, the construction of transition pathways together with stakeholders requires an exploratory approach (what are the problems, what is the vision for the future and what are possible solutions). This can be combined with a back-casting approach (what steps do we have to take to connect the future vision and the current situation). Kok et al. (2011) studied the combination of these two approaches and concluded that "it us conceptually appealing, methodologically feasible, and practically useful to combine exploratory scenario development and back-casting analysis" (p. 835). Furthermore, they have summarized this approach in a scheme, see Figure 3.

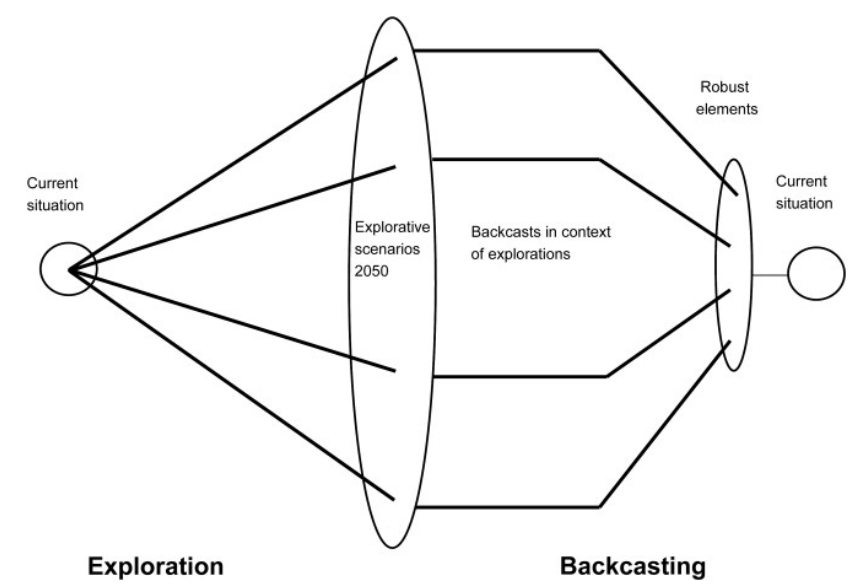

Figure 3 Combining exploration and back-casting (Kok et al. 2011) 


\section{Socio-technical scenarios}

When a transition has a strong technical element, socio-technical scenario building can aid in exploring potential transition pathways. Socio-technical scenarios (STScS) are based on transition theory and consider the interactions between niches, regimes and (socio-technical) landscapes. Within the STSs method, two contrasting scenarios are formed, a 'business-as-usual' scenario in which new technologies diffuse in an expected way, and a scenario with a lot of social change. The outcome of the STSc is thus predefined, but the aim is to analyze the factors that will lead to one scenario or the other (Elzen, Geels, and Hofman 2002). The STSc method uses three general steps:

- $\quad$ Step 1: Vision building: develop one or more future visions (e.g. for the year 2035 or 2050) of a sustainable system for the domain of interest;

- $\quad$ Step 2: Back-casting: Develop a set of plausible 'transition pathways', i.e. a set of innovation and change processes that lead from the present situation to the future visions;

- Step 3: Reflection: Reflect on the transition pathways by zooming in to the role of specific stakeholders of interest and what they can do under various circumstances to help realize more sustainable visions.

\subsubsection{Participatory design}

Participatory design includes the methods to design (making a plan or specification for the construction of an object or system) that invites all stakeholders (e.g. customers, employees, partners, citizens, consumers) into the design process as a means of better understanding, meeting, and sometimes preempting their needs. Participatory design fits in an open science, multiple stakeholder approach.

\section{Reflexive Interactive Design}

A method which can be used in collaborating with stakeholders on innovations is Reflexive Interactive Design (Reflexief Interactief Ontwerpen (RIO, Dutch)) (Bos 2010). RIO is about designing in a structured manner, based on transdisciplinary principles, together with practitioners. The aim of RIO is not only technical improvement or new technical solutions, but also the creation of ownership for practitioners. RIO is really a process, which also leads to new networks, and therefore new collaborative project. The core assumption of RIO is that what we currently consider as trade-offs in technical design, is only reflecting the societal goals of the past. We tend to continue thinking with current goals and paradigms as a basis when we are trying to design for current day solutions. Therefore, it always starts with the formulation of new goals and a new system analysis (see Figure 4). During this process, RIO facilitators try to make all underlying assumptions of these new goals explicit. The further process of RIO is very technical, but the main aim is to integrate engineering with stakeholder engagement and therefore to make technical innovation relevant to its future adopters. 


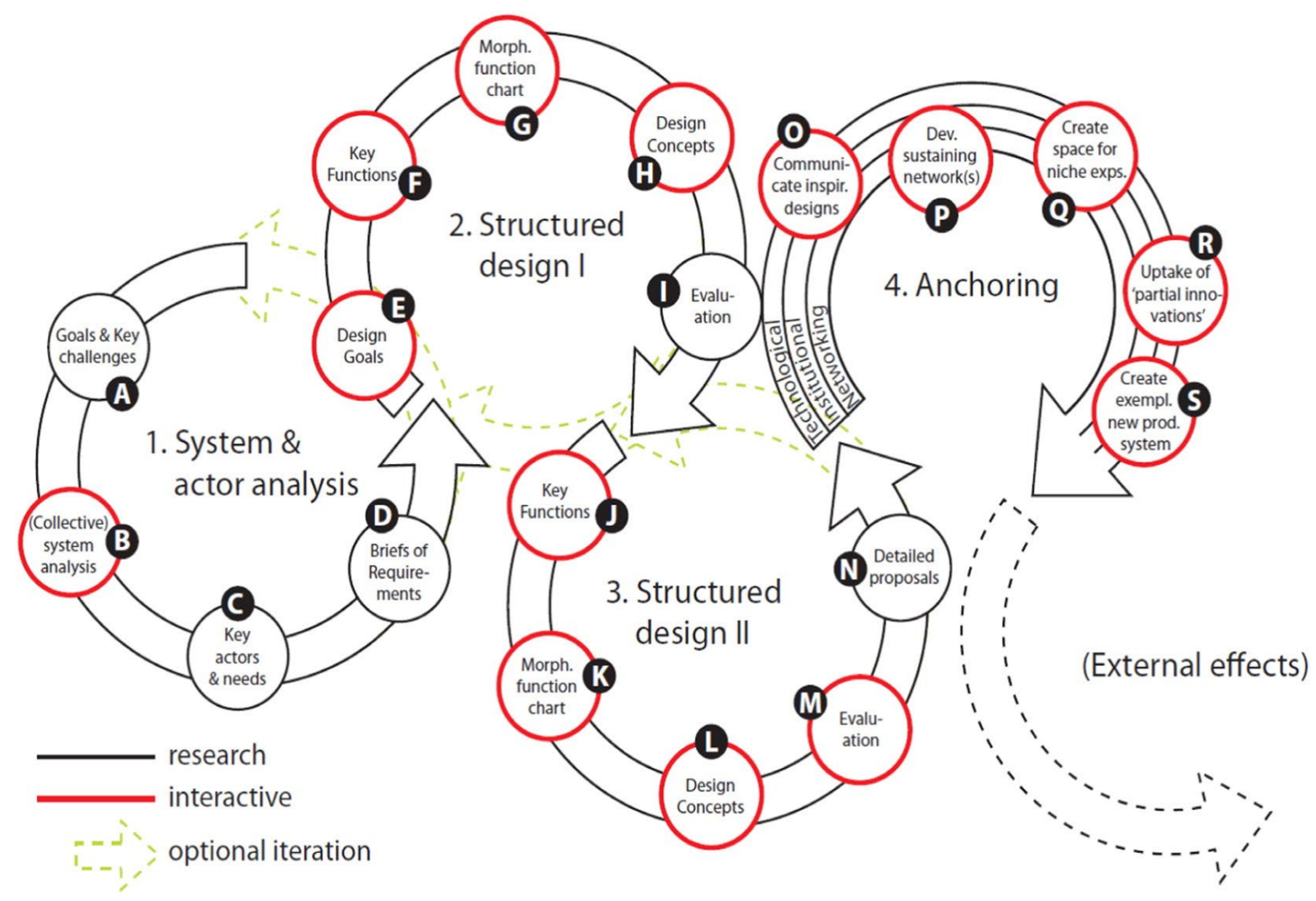

Figure 4 The four iterative steps of the RIO process (Elzen and Bos 2019)

\subsubsection{Participatory 'research in process'}

\section{Reflexive monitoring in action}

When studying innovation and transitions, the guidelines of the guidebook for reflexive monitoring in action are a useful reference (Van Mierlo et al. 2010). Tools that are described in this guidebook are for example the collective system analysis, the dynamic agenda and the timeline of most significant change. The aim of reflexive monitoring in action is to use reflection during system innovations processes, to be able to change and contribute to innovation during the process. Therefore reflective monitoring is not a separate activity, but it is part of the system innovation process (Van Mierlo et al. 2010). Reflective monitoring requires a long-time investment, which is inherent on working on transitions.

\section{Soft Systems Methodology}

The Soft Systems Methodology (SSM) is developed by Peter Checkland. He tried to find a method which bridges the language of experts and the language of users and practitioners (Checkland 2002). Soft Systems Methodology (SSM) aims at improving situations in which wicked problems make it impossible to choose for a simple solution (Lewis 1992). Such situations, where trade-offs are not clear and cannot be easily made, can be explored by focusing on the different sets of values, beliefs and norms which stakeholders have and which relate to the situation. By developing problem definitions and debating and discussing changes that would be possible, relevant and wished for by the stakeholder groups, SSM can aid in understanding what changes are needed to come to a transition. Through the SSM process, researchers conduct two studies, which are interlinked with each other. On the one hand, a researcher studies the perceptions of stakeholders and the issues they identify. On the other hand, the researcher will study the role of social interactions, power relations and politics within the identified problems and the transition process (Lewis 1992). An overview a possible pathway for SSM is described in Figure 5. 


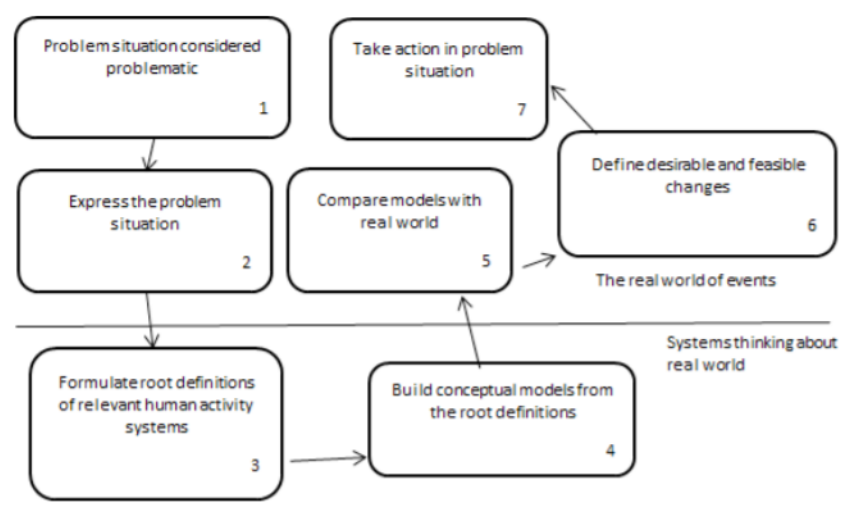

Figure 5 Soft systems methodology (Checkland 2002, p. 160)

\section{Theory of Change}

Another method, which can be used to develop interventions in a system, is Theory of Change (ToC) (Morra Imas \& Rist, 2009). Theory of Change is a description of how and why a desired change is expected to happen in a context. ToC can be used to study and evaluate the theory which forms the basis for a specific intervention or developmental program, or it can be used to develop a certain program or intervention, in which case it is more of an approach than a research method. By studying and analyzing a program, its ToC and how it is put into practice, you can systematically assess whether failures are a failure of theory (the logic behind the ToC does not make sense ) or whether it is a failure of practice (the program is not conducted in a right way). This can be done ex-ante, for instance as a tool in planning interventions, but also ex-post, as an evaluation. As a researcher, assessing a ToC ex-ante can help in co-creation of the goal of the intervention/transition and in developing the interventions itself, together with the client. What is very important when assessing a $\mathrm{ToC}$, is that the assumptions behind it are critically studied and if possible tested before developing interventions. The core of a transition is often behavioral change. Not only at a farmer or fisher level, but also on the level of organizations and governments. Assumptions underlying behavioral change are nonetheless rarely tested. Researchers and organizations assume for instance that if a better or more healthy food product is available, people will replace the less healthy product with the new one. But the social and cultural context is hereby totally neglected. Therefore, adaptation rates of all kinds of interventions are generally low. If a transition is based on an important behavioral change, such as the adaptation of new farming practices when these have been developed by a university, first it has to be determined whether these farmers are open to adopting new practices, and whether they regard new practices as a solution to what they regard as the problem within the or their system.

\section{Living labs}

Living lab is a research method in which new technology, new practices of new policies are evaluated in a multi-disciplinary manner in real life situations. The difference between a living lab and a field lab, is that a learning process together with stakeholders is an integral part of a living lab. At Wageningen Research, this method is used to study human behavior in relation to food and climate. As behavior is often less rational than we expect, the living labs study the social processes that influence behavioral change, in relation to the food system. The aim of a living lab is to understand individual behavior better, to develop better interventions for the food system (Onwezen et al. 2019). An example of a living lab is the living lab for cacao, where the adoption of new technologies by cacao farmers is studied. Development programs often choose their participants (in this case farmers) randomly, without considering the chance that the farmer will adopt the technology. By studying the characteristics of farmers that have a high chance of adopting a new technology in a real-life experiment, developmental programs can become more effective (Beekman and Voors 2020). 


\subsection{Tools}

In the introduction we distinguished in general three types of tools which are specifically relevant for transition pathway development: selection tools, evaluation tools and envisioning and forecasting tools. Within science, there are many tools that can be used in stakeholder engagement in transition pathway development in food system transitions. Based on research experience of the participating researchers, we chose relevant examples for the specific situation of pathway development in food system. In this section we thus provide some well- and sometimes lesser known examples; the stakeholder analysis using an interest-power grid, a SWOT-analysis and food system decision-support tool, rich picture, the Plan Intégré du Paysan and the Four Quadrants of Change.

\subsubsection{Selection tools}

Deciding which stakeholders to involve in the development of transition pathways is a difficult but crucial task. A stakeholder analysis can help with that and is a good way of preparing your research before actual stakeholder engagement takes place. Stakeholder analysis is a tool to identify relevant stakeholders and to evaluate their actual or potential position. While stakeholder analysis is a tool in many project management methods, there are also many ways of performing a stakeholder analysis. For example the Q methodology, stakeholder-led stakeholder categorization and Social Network Analysis (Reed et al. 2009). A relatively simple but useful approach is the interest-power grid, which is a top-down analytical approach. To do the analysis, interviews, questionnaires or focus groups can be used. Interest is positioned on the $\mathrm{Y}$-axis and represents interest in a political sense. Power is positioned on the X-axis and represents power in the sense of influence, what power does the stakeholder have to influence the issue at stake. By dividing both axes into low and high, four categories of stakeholders emerge: players (high interest power), subjects (high interest but little power), context setters (little interest but substantial power) and the crowd (low interest and power) (Bryson 2004). When choosing participants, it is important to consider stakeholder groups that have high interest and/or high power, as these people are affected or determine the success or failure of a food system transition (see Figure 6).

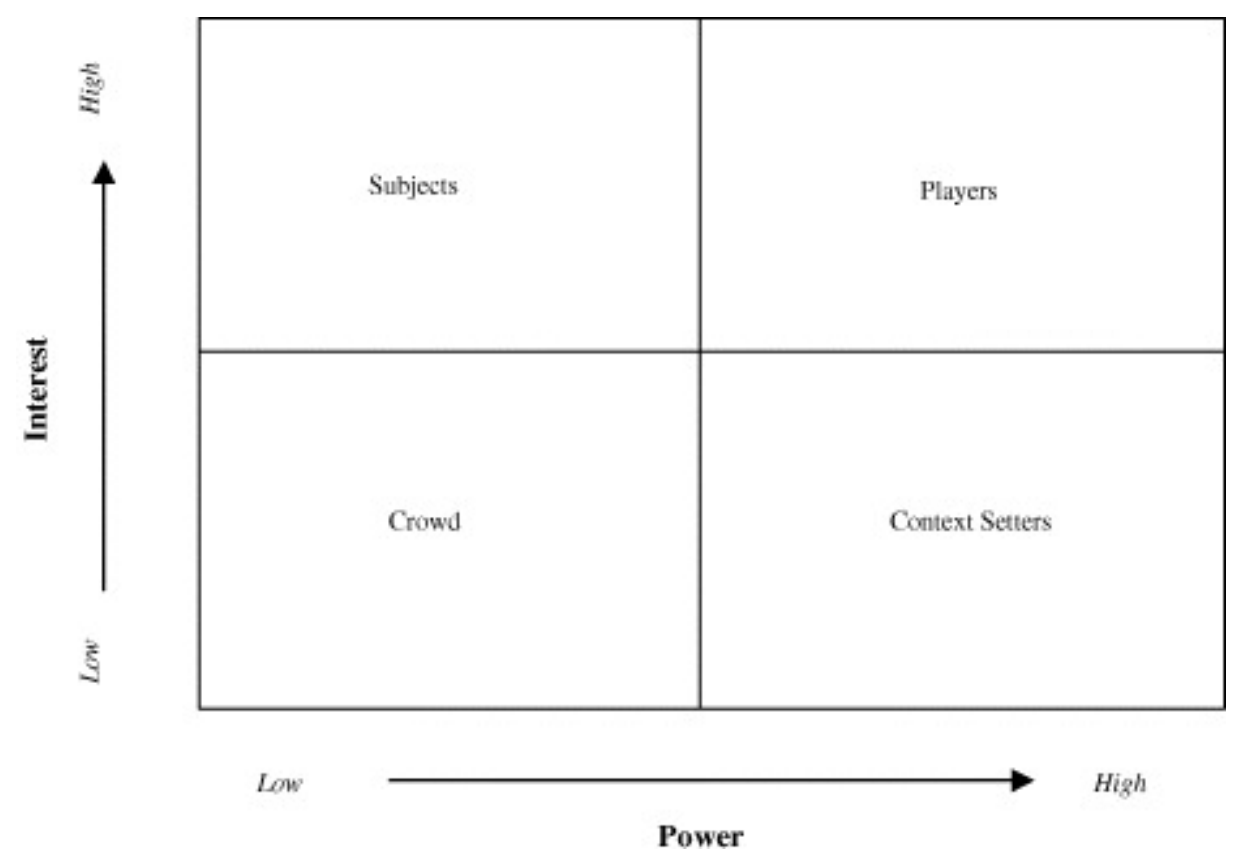

Figure 6 Power versus interest grid (Bryson 2004).

\subsubsection{Evaluation tools}

\section{SWOT-analysis}

A classical but useful way of starting the transition pathway development process, is by conducting a SWOT-analysis of the food system. After a vision or goal has been established, the current system can 
be evaluated and strengths, weaknesses, opportunities and threats can be identified. A SWOT-analysis is suitable for including different types of stakeholders, for instance through facilitated workshops (Rimmer et al. 2013). Through a participative workshop, different perspectives on the food system can be included. In combination with an analysis of the food system based on literature, a SWOT-analysis can form a good basis for developing transition pathways to the desired (policy) goals.

\section{The food system decision-support tool}

A tool which is more specifically aimed at analysing food systems and using this analysis to develop effective policy measures is the food system support tool. The food systems decision-support tool is based on the food systems approach and aimed at aiding policy makers in the development of effective policy measures for food and nutrition security (FNS). The support tool describes the steps of doing a thorough food systems analysis, thereby focussing in underlying mechanisms and archetypical behaviour of the system. The support tool consists of 7 steps, which start and end with the policy goals regarding FNS (see Figure 7). By understanding the mechanisms of the system and identifying leverage points, effective policy measures can be identified. Input for the tool is based on literature as well as on policy and expert workshops (Posthumus et al. 2018).

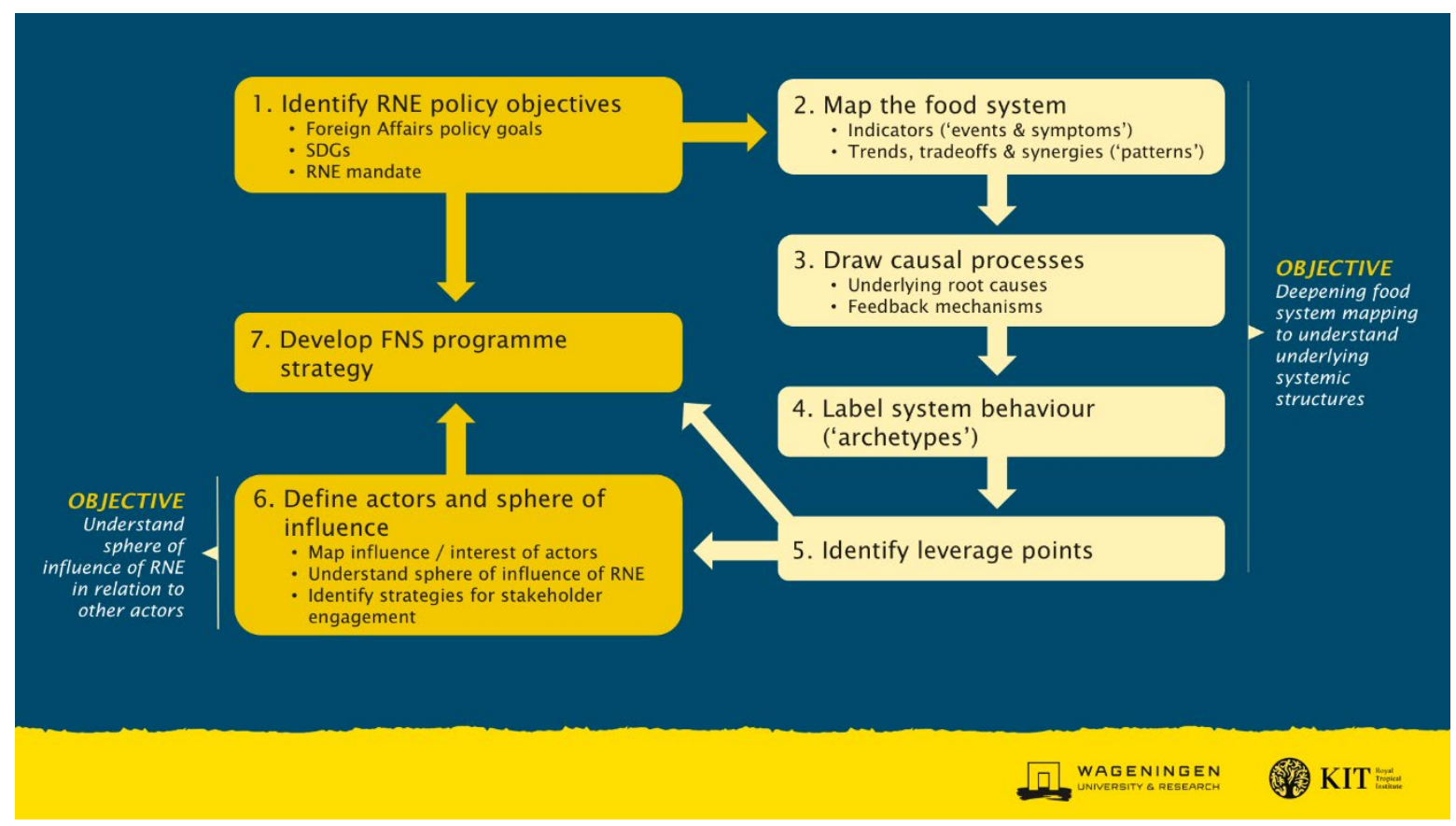

Figure 7 The food system decision-support tool (Posthumus et al. 2018)

\section{Rich picture}

Within the Soft Systems Methodology, rich pictures are often used to visualize the problems as identified during the SSM process. The rich picture is therefore based on a thorough study on the different perceptions and viewpoints on the problems of a specific system, but also on the social and political context of the system. A researcher can use a rich picture to structuralize his analysis of the situation and the apparent problem (Sani, Prasojo, and Atmoko 2017). This rich picture does not only assist in the analysis, but can also aid in communication with stakeholders (Durrant et al. 2016). Figure 8 shows an example of a rich picture, in this case about the ecosystem management and restoration of a watershed in Indonesia. 


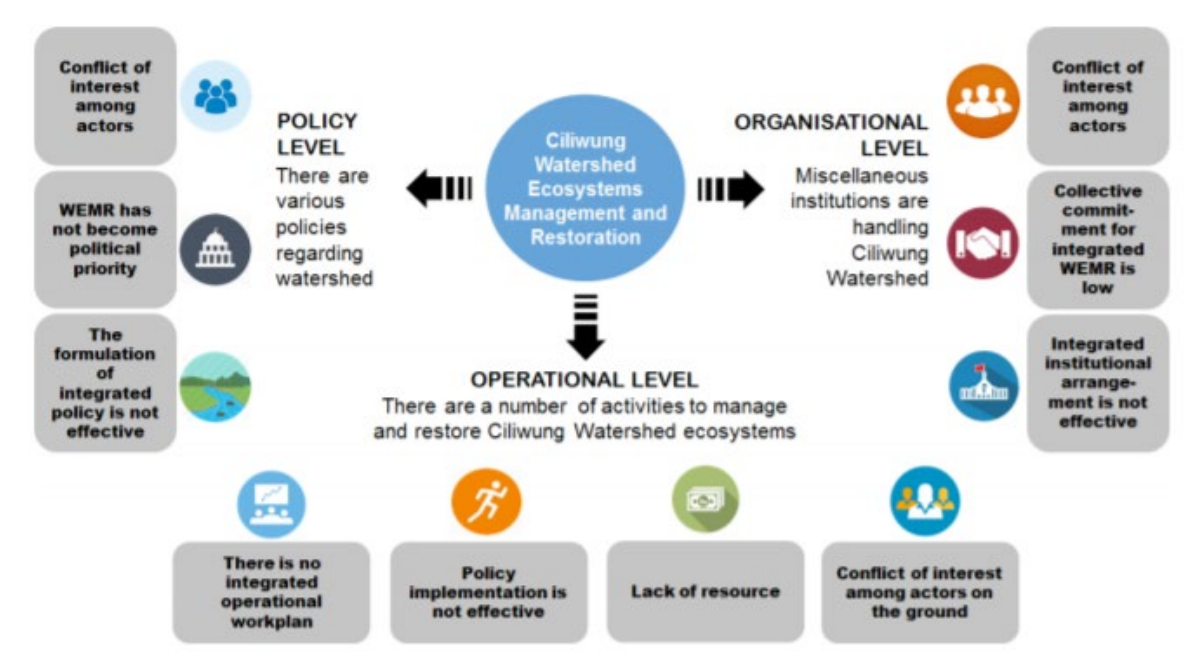

Figure 8 Rich picture example (Sani, Prasojo, and Atmoko 2017)

\subsubsection{Envisioning and forecasting tools}

When using methods like interactive forecasting or back-casting, there are different techniques that can be used to work with stakeholders within this method. Especially when formulating a future vision or a goal for a transition, there are many different options.

\section{Plan Intégré du Paysan}

Another tool which is useful especially when working with stakeholders that are not that vocal and outspoken about their position, is 'drawing the future'. Let people draw a future vision as answer to a question. For instance: how should your farm look like? Stakeholders can do this first on their own, after which it can be scaled up towards a family level and a village level. This can be done following the PIP-approach (Plan Intégré du Paysan (French)) aimed at fostering a sustainable food production system. It is based on making two drawings that visualize the current farm situation and the families desired future situation. These are drawn by all family members together and expresses their own aspirations and needs. This triggers discussion and reflection in a family (or a village) concerning their future, the role of the land and its resources. What flows from this is a common vision with a concrete action plan, and a change in mindset to invest in a more resilient farm - together. PIP has the potential to change the food system: from farmer-to-farmer, from village-to-village. Next to vision building, knowledge exchange is also an important part of the PIP-approach. Farmers visit each other and share new knowledge and innovations with each other (Kessler and Slingerland 2019). Photography can also be used. When discussing change, one could for instance ask stakeholders to take pictures of what they think characterizes the current system (for instance the farming practices) and let them discuss their pictures among their peers. Thereby you let people reflect on the current system, which can aid in understanding the possibilities for change.

\section{Four Quadrants of Change}

When discussing strategies for change, or transition pathways, with stakeholders, the 'four quadrants of change' can help in reflecting on why stakeholders opt for certain strategies and which strategies might be overlooked (WCDI 2020b). The four quadrants can facilitate in having a dialogue with stakeholders. The basis assumption is that to bring about change in complex systems, there must be a change in four dimensions (see Figure 9):
1. Spiritual-psychological
2. Inter-personal
3. Social and cultural
4. Structural and systemic 
A lack of change in one of the four dimensions, can hinder development in the other dimensions. Therefore, the quadrants of change can aid both stakeholders and researchers in exploration and reflection on possible and effective strategies for change.

\begin{tabular}{|c|c|c|}
\hline & Interior & Exterior \\
\hline Individual & $\begin{array}{l}\text { 1. Spiritual-Psychological } \\
\text { Concerned with changing one's own sense of being } \\
\text { Broad change theory: It's all a question of individual } \\
\text { perceptions and capacity. } \\
\text { Focus } \\
\text { - Deepening self-awareness } \\
\text { - Developing one's knowledge, skills, competencies } \\
\text { beliefs } \\
\text { Methods } \\
\text { - Meditation } \\
\text { - Personal reflection and inquiry } \\
\text { - Personal development of mastery through courses } \\
\text { and apprenticeships }\end{array}$ & $\begin{array}{l}\text { 2. Inter-Personal } \\
\text { Concerned with changing one's own behaviours in } \\
\text { interaction with others } \\
\text { Broad change theory: It's all a question of how } \\
\text { individuals interact. } \\
\text { Focus } \\
\text { - Showing trust, respect, mutual understanding } \\
\text { - Shifting behaviours to demonstrate } \\
\text { interdependence } \\
\text { - Reaching conciliation of inter-personal } \\
\text { differences } \\
\text { Methods } \\
\text { - Diversity training } \\
\text { - Learning journeys into other people's worlds } \\
\text { - Group encounters/retreats for exploration } \\
\text { Mediation/negotiations training }\end{array}$ \\
\hline Collective & $\begin{array}{l}\text { 3. Social and Cultural } \\
\text { Concerned with collective values of fairness and } \\
\text { justice } \\
\text { Broad change theory: It's all a question of collective } \\
\text { values and beliefs. } \\
\text { Focus } \\
\text { - Collective goals and aspirations } \\
\text { - Underlying values and beliefs } \\
\text { - Implicit 'rules' and assumptions } \\
\text { Methods } \\
\text { - Collective goal-setting and strategy creation } \\
\text { - Developing value statements and processes for } \\
\text { actualisation } \\
\text { - Ongoing media programmes }\end{array}$ & $\begin{array}{l}\text { 4. Structural and Systemic } \\
\text { Concerned with governance, decision-making } \\
\text { processes, and institutions. } \\
\text { Broad change theory: It's all a question of } \\
\text { processes, institutions, and power. } \\
\text { Focus } \\
\text { - Policies, legislation } \\
\text { - Institutions, procedures } \\
\text { Methods } \\
\text { - Building political structures, agreements, } \\
\text { - Neweworks, systems } \\
\text { systems }\end{array}$ \\
\hline
\end{tabular}

Source: Steve Waddell (2011, p 106) and Generative Change Community

Figure 9 The four quadrants of change (WCDI 2020b)

\section{Map Table}

In food systems, the spatial dimension is often of high importance (Berkum et al. 2020). Using a Map Table to draw plans, scenarios, visions during small group brainstorm and evaluation sessions can therefore be useful to promote participation of different stakeholders by using more interactively Geoinformation, to improve usability of maps in favor of participative projects and to detect and overcome knowledge gaps between different stakeholders (see Figure 10). A Map Table is useful wen working with small groups of stakeholders (2 up to 6 persons) (Van Lammeren 2020).

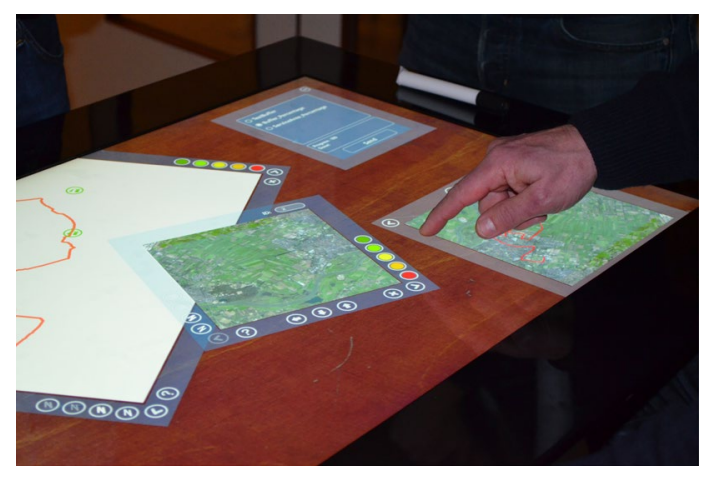

Figure 10 Picture of a Map Table (van Lammeren 2020) 


\section{General principles for the choice of approaches, methods and tools}

\subsection{Principles of responsible transition pathways}

Inspired by the Principles of Responsible Research and Innovation, we have formulated some principles for responsible transitions. Responsible Research and Innovation is a term used by the European Union to describe technological development that takes into account all societal an environmental impacts, next to the economy. In an extensive literature review Burget et al. (2017) mention inclusion, responsiveness, anticipation and reflexivity as distinct aspects of responsible innovation. Responsible innovation is criticized for its vagueness and not being practical, but apart from the direct applicability, it can certainly serve as a warning for environmental and societal risks.

The principles which we have identified are not more than a preliminary answer to the question of responsible pathways, but they do relate to aspects that are often mentioned in the used literature on approaches, methods and tools as rationale. In this paragraph we describe some principles, in the next paragraph we confront them with the inventoried approaches, methods and tools.

\section{Five principles}

We identified five general principles for responsible transition pathways in the literature on approaches, tools and methods. These principles are:

- Integral approach

- Inclusiveness and dialogue

- Contextuality

- $\quad$ Long term orientation

- $\quad$ Focus on tangible actions

\section{Integral approach: Methods and tools need to support an integral approach}

Within a food system transition, change will always occur in certain segments of the system. In many cases the focus lies on value chains, but the food system is more complex, which asks for a system approach rather than a chain approach. Figure 11 shows a conceptualization of such a system approach. Within this figure, the food supply system represents the value chain, but this is influenced by many other components of the food system. For methods and tools, the system approach implies that they must be responsive for: multiple actors, multiple scales and multiple places. Multiple actors mean that not only food producers, retailers or consumers are involved, but also for instance environmental organizations or cultural organizations. Multiple scales mean that the methods should connect problems and solutions on a local scale with requirements from and impacts on the surrounding regional scale, the regional scale with the national scale etc. Multiple places is related to multiple scales but focusses more on the tradeoffs from one place to another. A fine solution for waste in the Netherlands for instance can cause major environmental problem in a third world country where the waste is processed. 


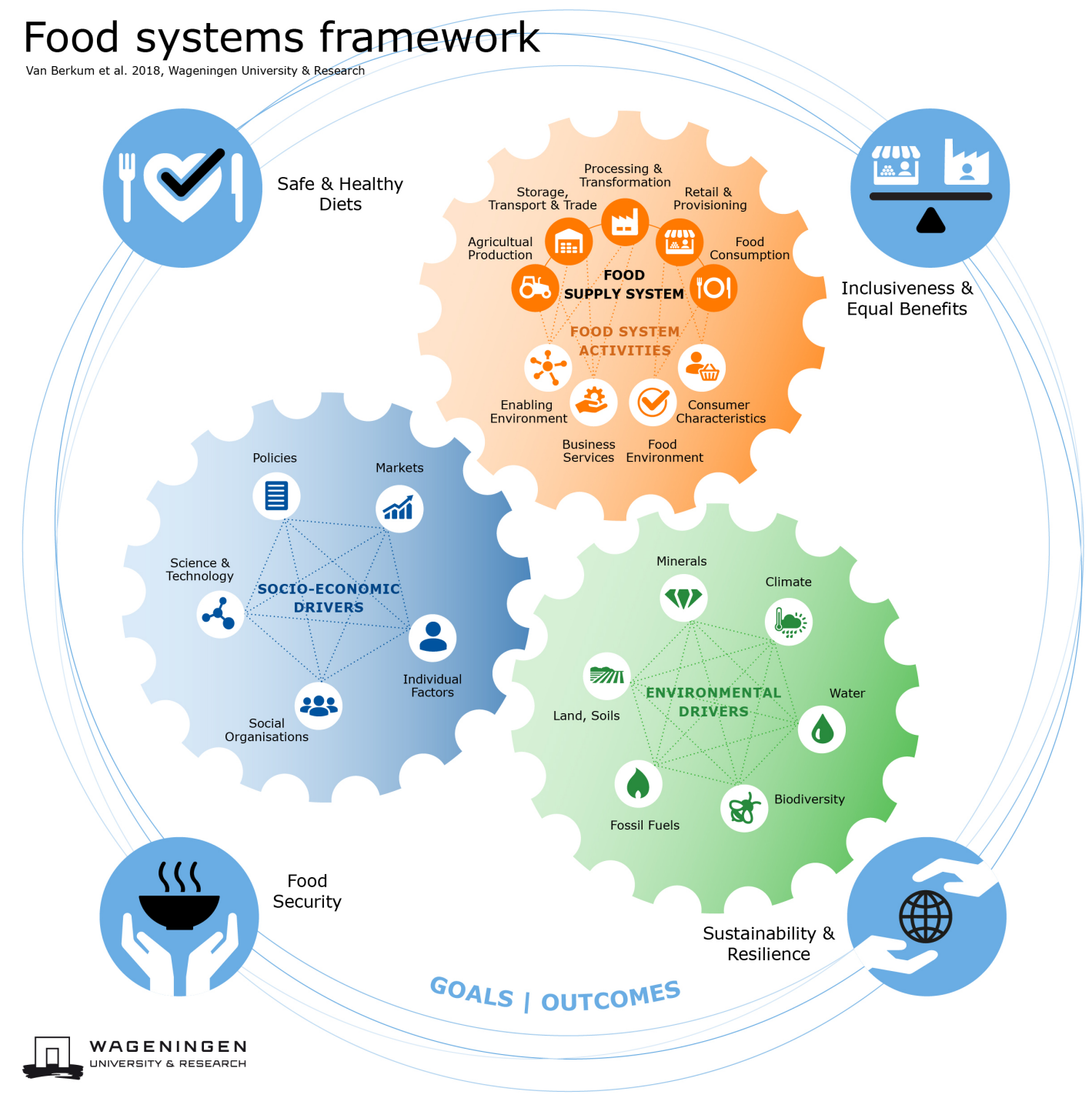

Figure 11 The Food Systems Approach (FSA) (Van Berkum, Dengerink, and Ruben 2018)

Inclusiveness and dialogue: Approaches, methods and tools should be inclusive, reflective and promote dialogue

To solve problems in the food system and create solutions and new opportunities, it is important that all relevant stakeholders are involved. The principle of inclusiveness applies here. Inclusiveness implies the directly involved people, but also the indirectly involved people who may have to deal with the effects of the food system. Furthermore, inclusiveness implies the engagement of not only formal representatives of organizations, but also people in other positions. But the broad involvement of stakeholders is not enough for long-term solutions. The approaches, methods and tools should also contribute to a dialogue, in which all stakeholders are taken seriously, can provide their own input and have a (shared) influence.

\section{Contextuality: Methods and tools should take cultural context into account}

Not all methods or tools work well in multiple cultural contexts. Method that work very well in the Netherlands does not have to work in a country elsewhere in the world that is part of the same food system. This is especially important for methods and tools for the engagement of stakeholders. The ways of communication can be very different, as can the hierarchical relationships or the access of stakeholders to the project. Methods should take the cultural context into account.

\section{Long term orientation: Methods and tools should anticipate the long term}

An important aspect of transitions is that they last for decades with al large range of variation.

Transitions such as the introduction of mobile phones went quite rapidly (one decade), while other 
transitions go much more slowly, such as electric cars. Furthermore, according to transition theory, transitions proceed in different phases: pro development, take off, breakthrough, stabilization (Rotmans, Kemp \& Van Asselt 2001). Each stage requires different approaches methods and tools. Therefore, engagement methods and tools need to adhere to either the aspect of time or the aspect of timing.

The first aspect, time, relates to the period that a tool is aimed at. Many stakeholder engagement tools are aimed at a specific period, for instance the duration of a research project. But a transition generally lasts very long, sometimes several decades, so when involving stakeholders, tools should be facilitating them to consider the long term.

The second aspect relates to timing. The different phases of a transition often involve different kind of stakeholders. For the choice of appropriate tools, one much consider the phase of transition and the arena of stakeholders. Generally, this means that a thorough stakeholders and systems analysis is needed before choosing stakeholder engagement tools.

Focus on tangible actions: Methods and tools should facilitate concrete actions for change Methods and tools should be aimed at supporting or facilitating change by concrete actions. The envisioning of transition pathways requires an understanding of future situations and of the kind of system change which could lead to such situations. Also, the use of stakeholder engagement tools requires an idea on the role of these stakeholders in the transition process. What concrete change do the stakeholders want to achieve? And how is this tool or activity contributing to concrete actions to achieve change? This might be the most challenging part of engaging stakeholders in transitions. It is important as researcher/organizer and stakeholder to understand how the tool can contribute to change in a desired way.

\subsection{Approaches, methods and tools and the five principles}

Table 2 gives an overview of the relationship between the approaches, methods and tools and the five principles. The table shows the extent to which they meet the five principles. This table does not lead to a sharp conclusion on the most appropriate approaches, methods and tools, but it does give an idea of the relevance of approaches, methods and tools for projects with stakeholders in the context of a food system transition.

Table 2. The five principles related to the approaches, methods and tools

\begin{tabular}{|c|c|c|c|c|c|}
\hline & $\begin{array}{r}\text { Integral } \\
\text { approach }\end{array}$ & $\begin{array}{c}\text { Inclusiveness } \\
\text { and dialogue }\end{array}$ & Contextuality & $\begin{array}{l}\text { Long term } \\
\text { orientation }\end{array}$ & $\begin{array}{r}\text { Tangible } \\
\text { actions } \\
\end{array}$ \\
\hline \multicolumn{6}{|l|}{ Approaches } \\
\hline \multicolumn{6}{|l|}{$\begin{array}{r}\text { Multi-Stakeholder } \\
\text { Partnerships (Action } \\
\text { research) } \\
\end{array}$} \\
\hline \multicolumn{6}{|l|}{$\begin{array}{r}\text { Transition Support } \\
\text { System Approach } \\
\text { (Stakeholder } \\
\text { participation and } \\
\text { decision support) }\end{array}$} \\
\hline \multicolumn{6}{|l|}{$\begin{array}{r}\text { Community of Practice } \\
\text { (Shared knowledge } \\
\text { creation) }\end{array}$} \\
\hline \multicolumn{6}{|l|}{ Issue Advocacy } \\
\hline \multicolumn{6}{|l|}{ Methods } \\
\hline \multicolumn{6}{|l|}{$\begin{array}{r}\text { Forecasting (Interactive } \\
\text { scenario building) }\end{array}$} \\
\hline \multicolumn{6}{|l|}{$\begin{array}{r}\text { Participatory mapping } \\
\text { (Interactive scenario } \\
\text { building) } \\
\end{array}$} \\
\hline QUICKScan & & & & & \\
\hline
\end{tabular}




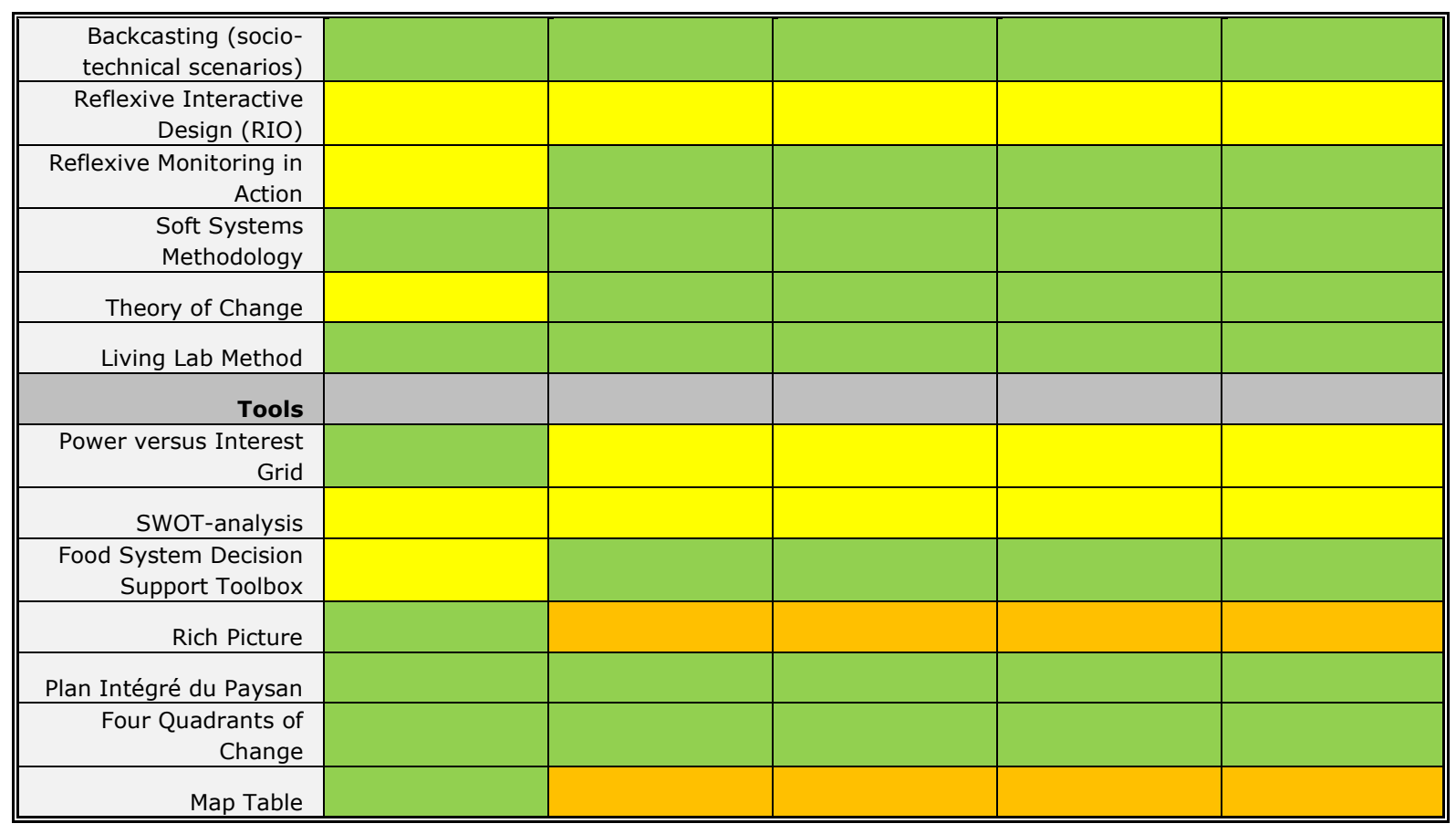

Green: in compliance with the principle; Yellow; partly in compliance with the principle; Red: not in compliance with the principle

\subsection{Different contexts for transition pathways}

The choice of approaches, methods and tools is determined by requirements from the context and to paradigmatic preferences of the researchers. Here we distinguish three different contexts for research projects that are aimed at food system transitions and work with stakeholders.

\section{Context: complex, many stakeholders with different views}

First, projects in complex situations with many contrasting views about the desired future. Debates in which the stakeholders think differently, not only on goals and desired futures, but also on theories. In many situations also the factual basis behind problems and possible solutions is contested. In this situation, approaches such as shared knowledge creation (p.15) and participatory research (p.14) are suitable.

Participatory research is useful for food systems transitions as it enables the researcher to incorporate the different perspectives on a transition within its research. However, as participatory research does not necessarily involve action, to make an impact on a transition the research should provide the client or the stakeholders with knowledge that is usable for making the desired transition. Therefore, action research (p.15) is more suitable for transitions, as (if done correctly) it is already aimed at achieving change. When choosing for action research, there are two types that are aimed at the long term: communities of practice and multi-stakeholder partnerships (p.15).

Within these approaches methods like reflective monitoring in action (p.21) and living labs (p.22) could work well while they closely connect the transitions process to the research process. When choosing for participative research, using the Theory of Change (p.22) can aid in creating interventions aimed at change. The Four Quadrants of Change (p.25) can aid stakeholders in deliberation on chosen pathways or strategies, and to encourage out-of-the-box thinking. With all tools, whether it are drawings or debating settings, it is important that there is enough time to discuss and evaluate what has been shown or discussed. The tool can serve as a way of understanding possible transition pathways or different futures, and engaging stakeholders in this process.

\section{Context: agreement on general direction and goals but less agreement on the pathways}

Second, situations in which there is a lot of debate, with both ambiguity and disagreement about the goals, but in which there is a general idea on the challenges. These are often projects in which plans are made for the development of an area, with an important role for the renewal of the food system. 
This often takes place in the context of government planning. A combination of data-driven and participative research can be very useful in this situation, especially in transitions, as models can aid in understanding the consequences of certain scenarios or pathways. An example of a relevant approach combining the two is the Transition Support System approach (TSS) (p.16). TSS is integral and very much aimed at change. Soft systems methodology (p.21) can aid in looking at an integral way at the proposed transitions, including scale and time. Both (interactive) forecasting and backcasting can be applied well here.

A method which is central in this document and very suitable for using in especially this situation is interactive back-casting (p.18), in which transition pathways are developed. This is very actionoriented, as it forces stakeholders to develop action perspectives, and at the same time explore possible futures. Whether it is incorporating scale, time and timing and integrality, is dependent on how it is practiced. However, the method itself really fits into participative or action research aimed at transitions.

Reflexive Interactive Design (p.20) is suitable when stakeholders within a transition see a real technological challenge, for instance when they are forced to abandon currently used techniques. But, as it is aimed at new innovations, when using it in transitions it should first be established whether a technical fix is needed, or whether the transitions is more of a social and political transition. The Food System Decision Support Toolbox (p.24) is specifically designed for food systems and can aid in guiding the process of system analysis, the exploration of scenario's and the assessment of interventions. This tool is mainly aimed at deliberation among policy makers and experts. A Map Table (p.26) can give direct visual feedback to stakeholders on strategies or decisions, which can aid the discussion.

\section{Context: support of disadvantaged groups}

Third, the situations in which the empowerment or development of a specific group is concerned: e.g. small farmers in a village or region, local fishermen, women in the village community, etc. Many years of research have made clear that they cannot be helped by only new techniques. An approach that fits in this situation is action research (p.15). There are two main categories of tools which are useful in transitions: visualizing the proposed or desired transition and deliberation between stakeholders on the proposed or desired transition. Visualizing can aid in understanding stakeholders and their desired transition but can also aid in deliberation between stakeholders. Visualization can be done via drawings, but also via photography. In addition, a tool like Plan Intégré du Paysan (p.25) is very suitable for this. Rich pictures (p.24) are also a form of visualization, often developed by the researchers themselves. 


\section{References}

Bebe, Bockline O, Corné Rademaker, Jan Van Der Lee, and Charles Tonui. 2017. "Executive Summary: Sustainable Growth of the Kenyan Dairy Sector - A Quick Scan of Robustness, Reliability and Resilience." Wageningen University \& Research.

Beekman, Gonne, and Maarten Voors. 2020. "Gerichte Selectie van Ondernemende Boeren." Dossiers Wageningen Research. 2020. https://www.wur.nl/nl/Dossiers/Living-lab-overgedragsverandering/Living-lab-projectenoverzicht/Gerichte-selectie-van-ondernemende-boeren.htm.

Béné, Christophe, Peter Oosterveer, Lea Lamotte, Inge D. Brouwer, Stef de Haan, Steve D. Prager, Elise F. Talsma, and Colin K. Khoury. 2019. "When Food Systems Meet Sustainability - Current Narratives and Implications for Actions." World Development 113: 116-30. https://doi.org/10.1016/j.worlddev.2018.08.011.

Berkum, Siemen van, Jan Broeze, Marion Herens, Bertram de Rooij, Katrine Soma, and Lotte Roosendaal. 2020. "Urbanisation, Migration and Food System Transformations."

Berkum, Siemen van, Just Dengerink, and Ruerd Ruben. 2018. "The Food Systems Approach: Sustainable Solutions for a Sufficient Supply of Healthy Food." https://doi.org/10.18174/451505.

Blackmore, Chris. 2010. "Social Learning Systems and Communities of Practice". London: Springer. https://doi.org/10.1007/978-1-84996-133-2.

Bos, Bram (A.P.). 2010. "Reflexief Interactief Ontwerpen (RIO)." Wageningen University \& Research.

Brouwer, Herman, Minu Hemmati, and Jim Woodhill. 2019. "Seven Principles for Effective and Healthy Multi-Stakeholder Partnerships." ECDPM Great Insights Magazine 8 (1). https://ecdpm.org/greatinsights/civil-society-business-same-direction/seven-principles-effective-multi-stakeholderpartnerships/.

Brouwer, Herman, Jim Woodhill, Minu Hemmati, Karèn Verhoosel, Simone van Vugt, Herman Brouwer, Jim Woodhill, Minu Hemmati, Karèn Verhoosel, and Simone van Vugt. 2016. "The MSP Guide: How to Design and Facilitate Multi-Stakeholder Partnerships. The MSP Guide: How to Design and Facilitate Multi-Stakeholder Partnerships". https://doi.org/10.3362/9781780446691.009.

Bryson, John M. 2004. "What to Do When Stakeholders Matter: Stakeholder Identification and Analysis Techniques." Public Management Review 6 (1): 21-53.

https://doi.org/10.1080/14719030410001675722.

Burget, Mirjam; Bardone, Emanuele; Pedaste, Margus (2017). "Definitions and Conceptual Dimensions of Responsible Research and Innovation: A Literature Review". Science and Engineering Ethics. 23 (1): 1-19.

CDAIS. 2017. "Factsheets \& Tools." 2017.

Checkland, Peter. 2002. "System Thinking, System Practice, Includes a 30 Year Retrospective, 2002". Wiley, Chichester.

Competentiecentrum Transities. 2009. "Transitiepraktijk -Tools En Competenties." 2009. https://www.transitiepraktijk.nl/nl/experiment/method. 
Dentoni, Domenico, and Verena Bitzer. 2015. "The Role(s) of Universities in Dealing with Global Wicked Problems through Multi-Stakeholder Initiatives." Journal of Cleaner Production 106: 68-78. https://doi.org/10.1016/j.jclepro.2014.09.050.

Dijkshoorn-Dekker, Marijke, Vincent Linderhof, Thomas J.M. Mattijssen, and Nico Polman. 2020. "Food Secure Metropolitan Areas: The Transition Support System Approach." Sustainability (Switzerland) 12 (13). https://doi.org/10.3390/su12135376.

Durrant, Abigail C., Wendy Moncur, David S. Kirk, Diego Trujillo Pisanty, and Kathryn Orzech. 2016. "On Presenting a Rich Picture for Stakeholder Dialogue." In DRS2016: Future-Focused Thinking, 6:2183-2201. https://doi.org/10.21606/drs.2016.169.

Elzen, Boelie, Frank W. Geels, and Peter S. Hofman. 2002. "Sociotechnical Scenarios (STSc): A New Methodology to Explore Technological Transitions." NWO Report.

Elzen, Boelie, and Bram Bos. 2019. "The RIO Approach: Design and Anchoring of Sustainable Animal Husbandry Systems." Technological Forecasting and Social Change 145: 141-52.

https://doi.org/10.1016/j.techfore.2016.05.023.

Funtowicz, Silvio O., Ravetz, Jerome R., 1993. "Science for the post-normal age." Futures 24:739755.

GAP2. 2015. "The Methodological Toolbox." Connecting Science, Stakeholders and Policy. 2015. http://gap2.eu/methodological-toolbox/.

Geels, Frank W., and Johan Schot. 2007. "Typology of Sociotechnical Transition Pathways." Research Policy 36 (3): 399-417. https://doi.org/10.1016/j.respol.2007.01.003.

Gray, Bette. 2004. "Informal Learning in an Online Community of Practice." Journal of Distance Education 19 (1): 20-35.

Grin, John., Rotmans, Jan., \& Schot, Johan. (2010). "Transitions to sustainable development: new directions in the study of long term transformative change". Routledge.

Haasnoot, Tim, Marloes Kraan, and Simon R. Bush. 2016. "Fishing Gear Transitions: Lessons from the Dutch Flatfish Pulse Trawl." ICES Journal of Marine Science 73 (4): 1235-43.

https://doi.org/10.1093/icesjms/fsw002.

Hasso-Plattner Institute of Design at Stanford (d.school). 2020. "Stanford d.School." 2020.

https://dschool.stanford.edu/.

IIED 2020. "Participatory Learning and Action (PLA)". https://www.iied.org/participatory-learningaction-pla

INRA Transfert. 2019. "AgriLink." 2019. https://www.agrilink2020.eu/.

Jentoft, Svein, and Ratana Chuenpagdee. 2009. "Fisheries and Coastal Governance as a Wicked Problem." Marine Policy 33 (4): 553-60. https://doi.org/10.1016/j.marpol.2008.12.002.

Kessler, Aad, and Erik Slingerland. 2019. "The PIP Approach : Fostering Resilience-Based Stewardship." Wageningen. https://www.wur.nl/nl/Onderzoek-

Resultaten/Onderzoeksinstituten/Environmental-Research/Programmas/Duurzaamlandgebruik/Duurzame-productiesystemen/De-PIP-aanpak-trotse-boeren-betere-bodems-en-meervoedsel.htm.

Klerkx, Laurens, Andy Hall, and Cees Leeuwis. 2009. "Strengthening Agricultural Innovation Capacity: Are Innovation Brokers the Answer?" UNU-MERIT Working Papers. 
Kok, Kasper, M. van Vliet Mathijs, I. Bärlund Ilona, Anna Dubel, and Jan Sendzimir. 2011. "Combining Participative Backcasting and Exploratory Scenario Development: Experiences from the SCENES Project." Technological Forecasting and Social Change 78 (5): 835-51.

https://doi.org/10.1016/j.techfore.2011.01.004.

Lammeren, Ron J.A. van. 2020. "Map Table." Wageningen University \& Research. 2020.

https://www.wur.nl/en/Research-Results/Chair-groups/Environmental-Sciences/Laboratory-of-Geoinformation-Science-and-Remote-Sensing/Research/Modelling-visualization/Map-Table.htm.

Lewis, Patrick. J. 1992. "Rich Picture Building in the Soft Systems Methodology." European Journal of Information Systems 1 (5): 351-60. https://doi.org/10.1057/ejis.1992.7.

Lowe, Philip, Phillipson, Jeremy, \& Lee, Richard P. (2008). "Socio-technical innovation for sustainable food chains: roles for social science". Trends in Food Science \& Technology, 19(5), 226-233.

Mackinson, Steven, S. Raicevich, M. Kraan, R. Magudia, and K. Borrow. 2015. "Good Practice Guide: Participatory Research in Fisheries Science."

McKee, Annie, Kirsty Holstead, Lee-Ann Sutherland, Teresa Pinto-Correia, and Maria Helena Guimaraes. 2014. "'Shift Happens': Co-Constructing Transition Pathways towards the Regional Sustainability of Agriculture in Europe." 11th European International Farming Systems Association Symposium.

https://www.researchgate.net/profile/Maria_Guimaraes20/publication/273387262_'Shift_happens'_Co constructing_transition_pathways_towards_the_regional_sustainability_of_agriculture_in_Europe/links /550024750cf260c99e8f5cc5.pdf.

Mierlo, Barbara van, Barbara Regeer, Volkert Beekman, Joske Bunders, Tjard De Cock Buning, Boelie Elzen, Anne-Charlotte Hoes, and Cees Leeuwis. 2010. "Reflexive Monitoring in Action". Wageningen: Wageningen University \& Research, VU University.

Morra Imas, Linda G., and Rist, Ray (2009). "The road to results: Designing and conducting effective development evaluations". The World Bank.

Onwezen, Marleen, Katell Hamon, Carolien de Lauwere, Stijn Reinhard, Marlene Roefs, Gonne Beekman, and Ruerd Ruben. 2019. "The Relevance of Behavioural Insights in a Transition towards a Healthy and Sustainable Food System." Wageningen.

Pielke Jr, Roger A. (2007). "The honest broker: making sense of science in policy and politics". Cambridge University Press.

Pohl, Christian, and Gertrude Hirsch Hadorn. 2007. "Principles for Designing Transdisciplinary Research." Swiss Academies of Arts and Sciences. https://doi.org/ISBN 978-3-86581-046-5.

Posthumus, Helena, Bart de Steenhuijsen-piters, Just Dengerink, and Sietze Vellema. 2018. "A Decision-Support Tool for the Design of Food \& Nutrition Security Programming: Bridging Concept and Practice in the Food System Approach."

Quist, Jaco, and Philip Vergragt. 2006. "Past and Future of Backcasting: The Shift to Stakeholder Participation and a Proposal for a Methodological Framework." Futures 38 (9): 1027-45. https://doi.org/10.1016/j.futures.2006.02.010.

Ravetz, Jerome, \& Funtowicz, Silvio. (2015). "Post-normal science. In Ethics of science in the research for sustainable development" (pp. 99-112). Nomos Verlagsgesellschaft mbH \& Co. KG.

Reed, Mark S. 2008. "Stakeholder Participation for Environmental Management: A Literature Review." Biological Conservation 141 (10): 2417-31. https://doi.org/10.1016/j.biocon.2008.07.014. 
Reed, Mark S., Anil Graves, Norman Dandy, Helena Posthumus, Klaus Hubacek, Joe Morris, Christina Prell, Claire H. Quinn, and Lindsay C. Stringer. 2009. "Who's in and Why? A Typology of Stakeholder Analysis Methods for Natural Resource Management." Journal of Environmental Management 90 (5): 1933-49. https://doi.org/10.1016/j.jenvman.2009.01.001.

Rimmer, Michael A., Ketut Sugama, Diana Rakhmawati, Rokhmad Rofiq, and Richard H. Habgood. 2013. "A Review and SWOT Analysis of Aquaculture Development in Indonesia." Reviews in Aquaculture 5 (4): 255-79. https://doi.org/10.1111/raq.12017.

Röckmann Christine, Judith van Leeuwen, David Goldsborough, Marloes Kraan, Gerjan Piet, 2015. "The interaction triangle as a tool for understanding stakeholder interactions in marine ecosystem based management." Marine Policy 52: 155 - 166.

Rotmans, Jan, Kemp, Rene, \& Van Asselt, Marjolein. (2001). "More evolution than revolution: transition management in public policy". Foresight-The journal of future studies, strategic thinking and policy, 3(1), 15-31.

Rut, Monika, Anna R. Davies, and Huiying Ng. 2020. "Participating in Food Waste Transitions: Exploring Surplus Food Redistribution in Singapore through the Ecologies of Participation Framework." Journal of Environmental Policy and Planning 0 (0): 1-14.

https://doi.org/10.1080/1523908X.2020.1792859.

Sani, Rasio Ridho, Eko Prasojo, and Andrereo Wahyudi Atmoko. 2017. "A Rich Picture of the Problem and Value Chain of Integrated Ciliwung Watershed Ecosystems Management and Restoration." Development and Society 46 (3): 427-49. https://doi.org/10.21588/dns/2017.46.3.002.

Smith, Adrian, and Andy Stirling. 2008. "Social-Ecological Resilience and Socio-Technical Transitions: Critical Issues for Sustainability Governance." Brighton STEPS Centre Working Paper 8 (8): 1-25. https://doi.org/ISBN 9781858645425.

Sondeijker, Saartje, Jac Geurts, Jan Rotmans, and Arnold Tukker. 2006. "Imagining Sustainability: The Added Value of Transition Scenarios in Transition Management." Foresight 8 (5): 15-30. https://doi.org/10.1108/14636680610703063.

Steins, Nathalie A., Veraart, Jeroen A., Klostermann, Judith E.M. and Marnix Poelman. 2020. "Combining offshore wind farms, nature conservation and seafood: Lessons from a Dutch community of practice". Marine Policy. doi.org/10.1016/j.marpol.2020.104371

Peter Verweij, Sander Janssen, Leon Braat, Michiel van Eupen, Marta Pérez Soba, Manuel Winograd, Wim de Winter, Anouk Cormont, 2016. "QUICKScan as a quick and participatory methodology for problem identification and scoping in policy processes." Environmental Science \& Policy 66: $47-61$.

Verweij, Peter. 2020. "QUICKScan - Gezamenlijk Milieuproblemen En Oplossingen in Een Participatieve Omgeving in Kaart Brengen." Wageningen University \& Research. 2020. https://www.wur.nl/nl/product/QUICKScan-gezamenlijk-milieuproblemen-en-oplossingen-in-eenparticipatieve-omgeving-in-kaart-brengen-1.htm.

Wangel, Josefin. 2011. "Exploring Social Structures and Agency in Backcasting Studies for Sustainable Development." Technological Forecasting and Social Change 78 (5): 872-82. https://doi.org/10.1016/j.techfore.2011.03.007.

WCDI. 2020a. "Guiding Sector Transformation: Inclusive, Effective and Sustainable." 2020. https://www.wur.nl/en/Research-Results/Research-Institutes/centre-for-development-innovation/OurValue-Propositions/Guiding-Sector-Transformation.htm. 
WCDI. 2020b. "MSP Tool 24: Four Quadrants of Change Framework."

http://www.mspguide.org/tool/four-quadrants-change-framework\#

Winograd, Manuel, van Eupen, Michiel, Verweij, Peter J. F. M., Perez-Soba, Marta, Bastrup-Birk, Annemarue, Cugny-Seguin, Marie, \& Fons, J. (2013). Land changes scenarios - Towards an operational Quick Scan. Targeted application using Quick Scan toolbox. European Environment Agency. http://forum.eionet.europa.eu/etc-sia-consortium/library/2013_subvention/221_5_3_landchanges-scenarios-towards-operational-quick-scan 


\section{Appendix 1}

\section{Topic guide interviews with Wageningen Research researchers on stakeholder engagement in transitions}

\section{Participatory tools and methods}

- How much does your institute work together with stakeholders in research projects? (On a

regular base/occasionally etc.)

- Why do you choose to engage stakeholders in your project?

- How do you select stakeholders?

- How do you approach stakeholders?

- What kind of agreements do you make with stakeholders?

- What do you expect from stakeholders when they are participating?

- What do stakeholders in general expect from participation?

- Do you use specific guidelines for stakeholder participation?

- Is there a commonly used method for stakeholder participation in your institute?

- Do you have examples of approaches which were successful in engaging stakeholders?

- Do you have examples of approaches which were less successful?

- Is there experience in the institute in engaging stakeholders in (food) transitions?

- If yes:

- How were stakeholders engaged?

- $\quad$ Did this differ from stakeholder engagement in other types of projects?

- What would be a good advice for organizations which want to engage stakeholders in transitions?

\section{Design tools and methods}

- When engaging stakeholders in transitions, do you engage them in the development of transition pathways?

- How would you construct a transition pathway?

- What would be the starting point?

o How would the whole process look like?

o What kind of methods do you use? (mapping, scenario studies etc.)

o What methods do you prefer?

o What would you expect to be the results?

- What would be the role of stakeholders in the development (specific!)?

o What is your role as researcher in constructing these pathways?

\section{Management, co-ordination and communication tools and methods}

- Who is responsible for engaging stakeholders?

- Is there one contact person for stakeholders to reach?

- How do you keep in touch with stakeholders during the process?

- How do you monitor stakeholders experiences in the transition pathway development process?

- Do you evaluate the process together with stakeholders?

- How do you communicate the results to the stakeholders?

- $\quad$ After the development of the pathway, how do you keep stakeholders engaged in the transition? 


\section{Appendix 2}

\section{Tools for stakeholder engagement in food system transitions}

Through this form we aim to gather different tools which are used within Wageningen Research with regard to stakeholder engagement in projects related to food system transitions. Please fill in one form per tool, if you know several tools that are used within your institute, please fill them in separately (open the form again for the next tool). It is recommendable to share this form with other researchers from WR that use different tools for stakeholder engagement in food system transitions. This survey is part of the Transition pathways (KB-35-006-001) project.

1. Name of tool (Open question)

2. Can you give a short description of the tool? (Open question)

3. Can you provide us with author names and/or URLs of papers or reports that are related to this tool? (Open question)

4. WR institute(s) in which the tool is used (Multiple choice, multiple options possible)
a. WECR
b. WEnR
c. WFBR
d. WCDI
e. WBR
f. WMR
g. $W P R$
h. WLR
i. WFSR

5. Level of the tool (Multiple choice)

a. Research style/Approach (e.g. action research, participative research)

b. Methods (e.g. scenario development, stakeholder analysis)

c. Techniques (e.g. speed dating, formulations of timelines)

d. Combination of one of the above levels

6. What is the scale of the projects for which the tool is suitable? (Multiple choice, multiple answers possible)
a. Local scale
b. Regional scale
c. Global scale

7. Is the tool suitable for integral and/or sectoral projects? (Multiple choice, multiple answers possible)

a. Integral projects (e.g. focussing on different parts of the food system)

b. Sectoral projects (e.g. focussing on a specific commodity or value chain)

8. If applicable, in which phase(s) of food system transitions is the tool useful? (Multiple choice, multiple answers possible)
a. Pre-development phase (a variety of innovations are being developed that hardly affect the system)
b. Take-off phase (the system becomes unstable due to rapid and conflicting changes)
c. Acceleration or breakthrough phase (physical, economic, socio-cultural and institutional changes accumulate)
d. Stabilisation (the renewed system comes to a new dynamic equilibrium)

9. How does using the tool contributes to the transition? (Multiple choice, multiple answers possible)

a. It enables researchers and stakeholders to understand the character of the transition

b. It enables stakeholders to understand their position within the transition

c. It enables researchers and stakeholders to develop action perspectives for stakeholders 


\section{d. Other}

10. Which type of functions/organizations could use the tool for engaging stakeholders in food system transitions? (Multiple choice, multiple answers possible)
a. Researchers/Research institutes
b. NGOs (e.g. when collaborating with local people)
c. Governments (e.g. when stimulating a transition) 


\section{Justification}

Report C001/21

Project Number: 4318300138

The scientific quality of this report has been peer reviewed by the a colleague scientist and the head of the department of Wageningen Marine Research.

Approved: $\quad$ Dr. Ir. N.A. Steins Senior scientist

Signature:

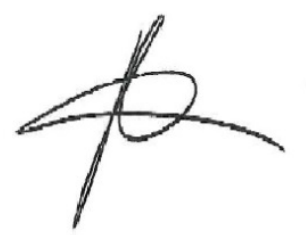

Date:

January $13^{\text {th }} 2021$

Approved:

Dr. Ir. T.P. Bult

Director

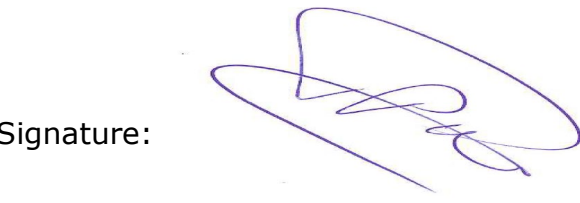

Date:

January $13^{\text {th }} 2021$ 
Wageningen Marine Research

T +31 (0)317480900

E: marine-research@wur.nl

www.wur.eu/marine-research

Visitors' address

- Ankerpark 271781 AG Den Helder

- Korringaweg 7, 4401 NT Yerseke

- Haringkade 1, 1976 CP IJmuiden
With knowledge, independent scientific research and advice, Wageningen Marine Research substantially contributes to more sustainable and more careful management, use and protection of natural riches in marine, coastal and freshwater areas.
Wageningen Marine Research is part of Wageningen University \& Research. Wageningen University \& Research is the collaboration between Wageningen University and the Wageningen Research Foundation and its mission is: 'To explore the potential for improving the quality of life' 